Western University

Scholarship@Western

\title{
Dynamic coupling of phase-heat and mass transfer in porous media and conjugate fluid/porous domains
}

Mahmoud Mohamed Mostafa Elhalwagy

The University of Western Ontario

Anthony G. Straatman

uwo, agstraat@uwo.ca

Follow this and additional works at: https://ir.lib.uwo.ca/mechanicalpub

Part of the Materials Science and Engineering Commons, and the Mechanical Engineering Commons

\section{Citation of this paper:}

Elhalwagy, Mahmoud Mohamed Mostafa and Straatman, Anthony G., "Dynamic coupling of phase-heat and mass transfer in porous media and conjugate fluid/porous domains" (2017). Mechanical and Materials Engineering Publications. 12.

https://ir.lib.uwo.ca/mechanicalpub/12 


\title{
Dynamic coupling of phase-heat and mass transfer in porous media and conjugate fluid/porous domains
}

\author{
Mahmoud Mohamed Elhalwagy, Anthony Gerald Straatman* \\ Department of Mechanical \& Materials Engineering, Western University, London, Ontario N6A 5B9, Canada
}

\section{A R T I C L E I N F O}

\section{Article history:}

Received 10 June 2016

Received in revised form 19 October 2016

Accepted 29 October 2016

Available online 14 November 2016

\section{Keywords:}

Dynamic coupling

Heat transfer

Mass transfer

Conjugate domains

Porous media

Computational fluid dynamics (CFD)

\begin{abstract}
A B S T R A C T
A dynamically varying technique for phase heat and mass transfer in porous media and fluid/porous domains has been developed and incorporated into a conjugate finite volume CFD framework. The local interstitial phase mass exchange within porous zones is estimated by comparison of the resistances to moisture transport within the solid and void constituents of the porous material; the higher resistance expression being used as rate-determining. Based on the mass transfer expression, a local estimate of the Biot number is used to physically apportion the withdrawal of vaporization energy from the solid and fluid constituents of the porous medium. A similar approach is used for coupling of the clear fluid and porous CFD cells at the clear fluid/porous interface. A phase ratio concept is introduced at these interfaces to be able to couple the different phases in heat and mass transfer. The model is generic, involving details that allow application to a wide range of cases and is one of the least empirically-adjusted models. The microscopic coupling approach has been validated for Coal packed bed drying. Results show good agreement with experimental data in terms of the matching trends and the small margins for temporal moisture and temperature variation. The macroscopic coupling technique has been tested using the cases of drying of an apple slice and the dehydration of mineral plaster. Investigating the two cases showed a clear difference in behavior as the apple slice case is material-side-resistance dominant - i.e. diffusively dominant - and the plaster case is air-side-resistance dominant - i.e. convectively dominant. The results are physically reasonable and compare well to available experiments and reported results from the literature. The comparisons indicate the capability of the present approach to model the dynamic coupling accurately in a computationally time-efficient manner.
\end{abstract}

(c) 2016 Elsevier Ltd. All rights reserved.

\section{Introduction}

Studies that involve heat and mass exchange in porous media are of significant practical interest and involve various applications. The importance of the subject has grown over the past decade and the computational fluid dynamics (CFD) capability of treating the microscopic heat and mass exchanges between the different phases of porous materials in an accurate and timely fashion is an active research topic. It is also necessary to develop rigorous techniques to couple porous materials to the surrounding moist air for computational modeling of heat and mass transfer. Such macroscopic coupling techniques should ensure accuracy and robustness as well as be computationally efficient. This will assist in the design of dryers and storage facilities for moist materials as well as enabling better forecasting for the quality of stored food-

\footnotetext{
* Corresponding author.

E-mail address: astraatman@eng.uwo.ca (A.G. Straatman).
}

stuffs, processing of building materials and the study of packed bed dryers, among other applications.

The modeling interest here is directed towards moist porous materials. A moist porous material is considered to contain a solid matrix, liquid water and void or moist air space i.e. (dry air and water vapor) [1,2]. Two sources of liquid water exist within the porous material: free liquid water that occupies the interconnected pores, and bound water within the solid constituent's closed micro-pores. As the moist material loses its moisture content, the closed pores open up and the bound water gradually becomes free. This process is correlated to changes in temperature and suggests the use of activation energy-type models [3-5]. Whether the material is hygroscopic (i.e. exhibits a high degree of moisture retention and gradual variation of moisture diffusivity, like most food stuffs) or non-hygroscopic (i.e. not considered to have a significant affinity for moisture and involves more sharp drops in moisture diffusivity, like most building materials) [6], moisture transport within a porous material involves factors like vapor diffusion, liquid capillary forces and surface tension effects [7,8], and all of these factors 


\begin{tabular}{|c|c|c|c|}
\hline \multicolumn{4}{|c|}{ Nomenclature } \\
\hline$A$ & area, $\mathrm{m}^{2}$ & $x$ & axial direction \\
\hline$A_{f s}$ & specific surface area of porous media, $\mathrm{m}^{-1}$ & $x$ & phase index \\
\hline$a_{W}$ & water activity & Y & mass fraction \\
\hline$B$ & Spalding mass transfer number & $\alpha$ & vaporization energy apportioning factor \\
\hline$B i$ & Biot number & $\beta$ & enhanced vapor diffusion factor \\
\hline$c_{E}$ & inertia coefficient of porous media & $\delta_{\text {diff. }}$ & significant liquid diffusion thickness, $\mathrm{m}$ \\
\hline$c_{p}$ & specific heat at constant pressure in fluid region, $\mathrm{J} / \mathrm{kg} \mathrm{K}$ & $\mu$ & dynamic viscosity, $\mathrm{N} \mathrm{s} / \mathrm{m}^{2}$ \\
\hline$c_{p s}$ & specific heat inside solid phase, $\mathrm{J} / \mathrm{kg} \mathrm{K}$ & $\rho_{s}$ & density of solid, $\mathrm{kg} / \mathrm{m}^{3}$ \\
\hline$D$ & binary diffusion coefficient, $\mathrm{m}^{2} / \mathrm{s}$ & $\rho_{f}$ & density of fluid mixture, $\mathrm{kg} / \mathrm{m}^{3}$ \\
\hline$D$ & bed diameter, $\mathrm{m}$ & $\varepsilon$ & porosity \\
\hline$d_{P}$ & particle diameter, $\mathrm{m}$ & $\varphi$ & a quantity \\
\hline$\dot{H}$ & enthalpy phase exchange term, $\mathrm{W}$ & $\langle\varphi\rangle$ & extrinsic volume-average of $\varphi$ \\
\hline$h$ & specific enthalpy, $\mathrm{J} / \mathrm{kg}$ & $\langle\varphi\rangle^{x}$ & intrinsic volume-average of $\varphi$ \\
\hline$h$ & bed height, $\mathrm{m}$ & & \\
\hline$h_{f g}$ & latent heat of evaporation at $0^{\circ} \mathrm{C}$ in fluid region, $\mathrm{J} / \mathrm{kg}$ & \multicolumn{2}{|c|}{ Subscripts and superscripts } \\
\hline$h_{f s}$ & $\begin{array}{l}\text { interfacial heat transfer coefficient in porous media, } \\
\mathrm{W} / \mathrm{m}^{2} \mathrm{~K}\end{array}$ & diff. & air \\
\hline$h_{f s m}$ & $\begin{array}{l}\text { interfacial mass transfer coefficient in porous media, } \\
\mathrm{m} / \mathrm{s}\end{array}$ & $\begin{array}{l}\text { E } \\
e\end{array}$ & $\begin{array}{l}\text { control volume on the east side } \\
\text { energy }\end{array}$ \\
\hline$i$ & species counter & $e$ & east cell integration face \\
\hline$k$ & thermal conductivity, $\mathrm{W} / \mathrm{m} \mathrm{K}$ & eff & effective property in porous media \\
\hline$K$ & Darcy permeability of porous media, $\mathrm{m}^{2}$ & $f$ & fluid \\
\hline K & phase ratio & $f l$ & fluid side of interface \\
\hline$m$ & mass, $\mathrm{kg}$ & fs & at fluid/solid interface (microscopic interface) \\
\hline$\dot{m}$ & mass flow rate, $\mathrm{kg} / \mathrm{s}$ & interf. & macroscopic interface \\
\hline$n$ & outward normal unit vector & $m$ & mass transfer \\
\hline $\mathrm{Nu}$ & Nusselt number & macro. & at fluid/porous interface (macroscopic interface) \\
\hline$P$ & pressure, Pa & $P$ & control volume over which the equation is being inte- \\
\hline $\operatorname{Pr}$ & Prandtl number & & grated \\
\hline$R$ & gas constant, $\mathrm{J} / \mathrm{kg} \mathrm{K}$ & por & porous side of interface \\
\hline $\operatorname{Re}$ & Reynolds number & $S$ & solid \\
\hline RH & relative humidity & sat & saturation \\
\hline Sc & Schmidt number & sol. & solid particle surface \\
\hline Sh & Sherwood number & $T$ & heat transfer \\
\hline$T$ & temperature, $\mathrm{K}$ & $v$ & vapour \\
\hline$t$ & time, $s$ & $W$ & water \\
\hline $\mathbf{v}$ & fluid velocity $[=(u, v, w)], \mathrm{m} / \mathrm{s}$ & & \\
\hline V & volume, $\mathrm{m}^{3}$ & & \\
\hline
\end{tabular}

are functions of moisture content and temperature. Adding the difficulty of coupling clear fluid regions with the porous material itself, and the dynamic nature of the changes in moisture content near the macroscopic interfaces, physical modelling becomes a significant challenge, and a compromise must be struck between the microscopic and macroscopic scale information to avoid making simulation models too computationally expensive.

The current state of the literature for the coupling of clear fluid and porous regions in these types of problems varies across: drying kinetics, single-phase, uncoupled-phase and conjugate coupling of phases (see Ref. [9] for a detailed literature review on the topic). In the first category, an overall drying curve is determined for the moist material by either experimentally and/or semi-analytically utilizing the concept of overall drying effective diffusivity and Arrhenius-type drying expressions. Thus, by this approach, it is the overall phenomenon that is modelled, as opposed to discrete solutions of heat and mass transfer [10-14]. Models in the second category solve for discrete quantities, but use single-phase values to describe the presence of moisture or temperature in a CFD cell. Such models are not capable of resolving the liquid to vapor exchanges or the solid phase to fluid phase energy flux. This category of modelling is referred to as the Equilibrium approach for heat and mass transfer [15-18]. By this approach, a specified boundary flux for the fluid to porous regions is empirically assigned utilizing correlations for Nusselt and Sherwood numbers available in the literature. This method is capable of characterizing the overall heat and mass transfer, but is case specific and is dependent on empirical estimates of the fluxes assigned at the boundaries. For the uncoupled-phase approach, the local solution inside the porous material is still based on an equilibrium model, in which a single transport equation characterizes the two phases. As for the macroscopic interface treatment, both the clear fluid region and the porous region are discretized and solved, however, they are uncoupled from one another. The fluid side solution is utilized to evaluate an interface heat transfer coefficient and through the Chilton-Colburn heat and mass transfer analogy, a mass transfer coefficient is obtained. These coefficients are then utilized as boundary conditions for the porous side solution [19-21]. The conjugate category of models mainly uses a non-simultaneous technique that solves each phase on its own, and then couples them explicitly by updating the fluxes at the boundaries at each time step [8,22]. This technique is effective, but similar to the uncoupled approach, computationally time-consuming due to its explicit nature. In addition, most of the work in the conjugate category either simplifies the porous material to a non-porous material - i.e. the technique typically neglects the gas transport inside the porous 
region - or is an equilibrium-type model that solves one entity to characterize the two phases. Implicit conjugate coupling has also been achieved. Lamnatou et al. [23] have used a simultaneous conjugate coupling technique for two dimensional convective drying simulations using a stream function formulation. This, however, restricts its application to two-dimensional simulations. Most recently, Khan and Straatman [9], presented an implicit conjugate approach for the simulation of produce drying. The model considers non-equilibrium heat and mass transfer, however, the macroscopic interface treatment involves empirical coefficients to characterize the changes in liquid and vapor mass transfer resistances, which are simulation dependent, i.e. changes with change of boundary conditions.

Local exchanges of heat and mass between the phases of porous materials have also been studied, however, generally they have been ignored in equilibrium-type models, or they are empirically adjusted for non-equilibrium models [24,25]. Particle and grain packed-bed studies have given the subject more practical interest mainly in terms of the dynamic nature of the change in mass transfer resistances that is more pertinent in these studies [26-30]. The state of the art in the literature is either to treat the surface of the solid constituent as fully-saturated with water vapor, i.e. $100 \%$ relative humidity [25], or to define water activity for the moist material. Where water activity is defined as the thermodynamic equilibrium value of the relative humidity at the surface of a wet particle, which is based on the particle's liquid moisture content and temperature $[6,15]$. The driving potential for mass transfer is then usually determined based on the surface-to-fluid vapor concentration difference, and local mass transfer coefficients that are functions of the nature of the flow and internal geometry of the porous material; and such models do not usually take the solidside resistance to mass exchange into account [15,25]. Another drawback is that these models only consider the diffusive effects in the fluid side resistance without consideration of advective effects, which are important in cases where the porosity and thus the evaporation rate can be high. The solid-side mass transfer resistance has been considered in different ways in the literature however, it mostly involves intensive empirical calibration of the resistance and is dependent on data from thin-layer or singleparticle kinetics' experiments [30-32]. The assumption of thermodynamic equilibrium, i.e. depending entirely on water activity to represent the solid side potential for mass transfer, is also utilised in different studies $[27,30,33]$. Whenever the surface of the solid constituent becomes relatively dry - i.e. when drying out becomes imminent - a liquid moisture front starts shrinking inside the solid constituent forming a dry layer at the solid surface. In these situations the thermodynamic equilibrium assumption is no longer valid, specifically in a macroscopic model that characterizes the local solid constituent moisture content with one moisture fraction value. In such a case it is not possible to split the solid constituent to a dry part and a wet part. It is also a common weakness in packed-bed drying models to have phase exchange techniques that are too complicated for time-efficient implementation in three dimensional models, i.e. such models are mainly onedimensional $[30,31,33]$. Another aspect to shift attention to the phase exchange processes is the moisture-accompanied heat exchanges, i.e. mass flux enthalpy exchange between the phases. The amount of heat that is withdrawn is the heat of vaporization associated with the mass transfer. Some existing models in the literature withdraw this energy entirely from the void (air-vapour mixture) constituent $[9,25]$. Such studies have been modeling evaporative cooling processes or cases that do not involve high temperature variation. Other cases - especially in packed beds, and problems with high thermal non-equilibrium - withdraw this energy entirely from the solid portion, since it is assumed that the liquid is mostly either bound inside the solid portion or due to high solid conductivity compared to the fluid side, both liquid and solid constituents are in thermal equilibrium $[27,30,32]$. This is another loss of generality as the physics of the process of evaporation dictates the withdrawal of vaporization energy from both phases in different proportions [34].

The present paper describes a computational technique for characterizing dynamic coupling of the phases in porous media applications which, to the best of the authors knowledge, has not yet been achieved. Herein, we define 'Dynamic Coupling' as an implicit, simultaneous, non-equilibrium approach for characterizing microscopic (interstitial) and macroscopic interfaces. In this manner, the interstitial heat and mass exchanges between the solid and fluid phases of the porous medium are captured, as well as those between the fluid and porous cells at macroscopic interfaces that separate fluid and porous regions of conjugate domains. The key to the approach is that interface heat and mass transfer resistances are formulated to vary locally and dynamically in response to changes that occur during the physical process under consideration. This approach removes the need for ad-hoc or empirical specification of the fluxes at the interfaces and nearly eliminates case-to-case calibration. In the remaining sections of the paper, the general formulation is first presented for the clear fluid and porous regions, followed by the approach developed for dynamic coupling at microscopic and macroscopic interfaces. The presence of a macroscopic interface has a strong influence on the heat and mass transfer phenomenon as it is often ratedetermining, especially in low porosity materials like food stuffs or building materials, and requires special attention in the formulation. Different cases for modeling dynamic coupling at the fluid/porous interfaces are then presented, followed by verification cases that demonstrate the viability of the formulation under various drying conditions.

\section{Model formulation}

The governing equations and mathematical conditions relevant to the conjugate modeling of fluid and porous regions as well as the interstitial and macroscopic phase coupling approaches are presented in this section. A simple depiction of a conjugate fluidporous domain is given in Fig. 1 to illustrate what is meant by fluid region, porous region and macroscopic interface. The porous region of the domain is comprised of solid and void (fluid) constituents, which interact via microscopic interfaces. The general formulation is adopted from the work of Khan et al. [25] with improvements and modifications discussed in the relevant subsections. The fluid

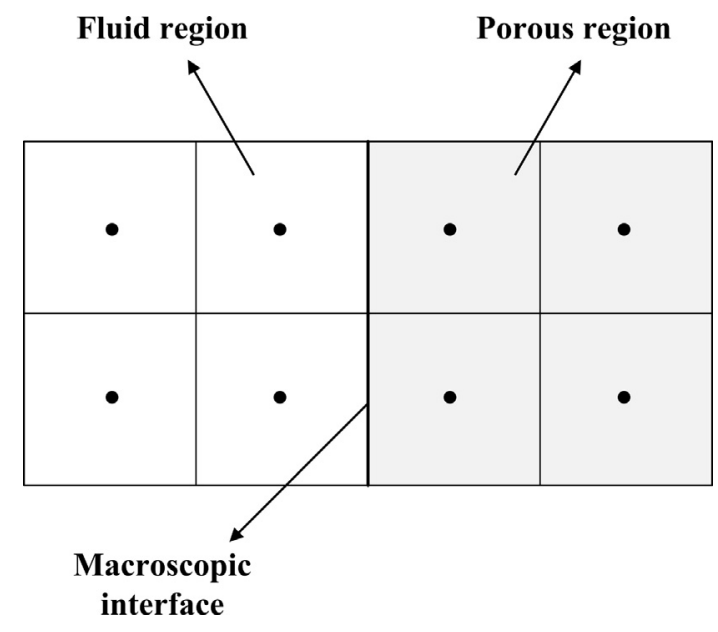

Fig. 1. A discrete conjugate Fluid-Porous domain. 
in the present formulation is assumed to be comprised of a mixture of dry air (i.e. includes all the dry gas species of atmospheric air) and water vapor and is referred to as 'moist air'. The flow is considered to be density-varying due to the change in the local vapor moisture content and the moisture transport phenomenon under study, characterized by the local vapor moisture mass fraction in the moist air $\left(Y_{v}\right)$. Expressions utilized for the mixture density $\rho_{f}$ and vapor moisture fraction $Y_{v}$ are

$\rho_{f}=\rho_{a}+\rho_{v}=\frac{P-\left(R H \cdot P_{s a t}\right)}{R_{a} T}+\frac{R H \cdot P_{s a t}}{R_{v} T}$

$Y_{v}=\frac{R H \cdot P_{s a t}}{\rho_{f} R_{v} T}$

where $\rho_{a}$ is the dry air density, $\rho_{v}$ is the vapor moisture density, $P$ is the local pressure, $R H$ is the local relative humidity, $P_{\text {sat }}$ is the saturation vapor pressure at the local temperature, $R_{a}$ and $R_{v}$ are the gas constants for dry air and water vapour, respectively, and $T$ is the local temperature of the fluid volume.

\subsection{Fluid region}

To fully characterize the fluid flow and heat and mass transfer in the fluid region, vapor (moisture) mass fraction $\left(Y_{v}\right)$ and energy equations are solved in addition to the Navier-Stokes and conservation of mass equations. In the absence of external forces, mass or heat sources, the equations of mass and momentum conservation, vapor moisture and fluid energy are given, respectively, as

$$
\begin{aligned}
& \frac{\partial \rho_{f}}{\partial t}+\nabla \cdot\left(\rho_{f} \mathbf{v}\right)=0 \\
& \frac{\partial\left(\rho_{f} \mathbf{v}\right)}{\partial t}+\nabla \cdot\left(\rho_{f} \mathbf{v v}\right)=-\nabla P+\mu_{f} \nabla^{2} \mathbf{v} \\
& \frac{\partial\left(\rho_{f} Y_{v}\right)}{\partial t}+\nabla \cdot\left(\rho_{f} Y_{v} \mathbf{v}\right)=\nabla \cdot\left(\rho_{f} D_{f} \nabla Y_{v}\right) \\
& \sum_{i} c_{p, i} \frac{\partial\left(\rho_{f} Y_{i} T\right)}{\partial t}+\sum_{i} h_{f g, i} \frac{\partial\left(\rho_{f} Y_{i}\right)}{\partial t}+\sum_{i} c_{p, i} \nabla \cdot\left(\rho_{f} Y_{i} T \mathbf{v}\right) \\
& \quad+\sum_{i} h_{f g, i} \nabla \cdot\left(\rho_{f} Y_{i} \mathbf{v}\right)=k_{f} \nabla^{2} T+\sum_{i} \nabla \cdot\left[\rho_{f} D_{f} \nabla Y_{i}\left(c_{p, i} T+h_{f g, i}\right)\right]
\end{aligned}
$$

Here, $i$ represents a counter of species, $c_{p, i}$ is the specific heat of species $i$ and is calculated with a reference at $0{ }^{\circ} \mathrm{C}$ for vapor moisture, and $h_{f g, i}$ accounts for the latent heat of vaporization at a reference temperature of $0^{\circ} \mathrm{C}$, which is of zero value for dry air. The formulation accounts for the sensible and latent portions of the mixture energy in separate terms for both the transient and advective terms [25]. This approach provides a means for reducing nonlinearity that is not needed in cases where the specific heat accounts for both types of energy. It is also a method that enables the control of convergence using different time steps [25]. We also include two terms for the energy diffusion: a conductive term and a term that accounts for the species energy diffusion or the species energy transfer accompanying mass transfer. This term is of special importance at macroscopic interfaces.

\subsection{Porous region}

The general framework of the porous model is based on the theory of volume-averaging for flow, heat and mass transfer by Whitaker [2]. In this framework, every representative elementary volume (REV) for the porous material includes a fluid or void phase, a solid phase, and a liquid phase with multiple microscopic interfaces between them. Following the approach by Khan et al. [25], a simplification is introduced in which only a single microscopic interface is considered between the moist air (void part) and the solid matrix which holds the liquid water. Thus, in this simplification, we consider bound water. We also consider the free water by allowing the variation of the effective liquid-in-solid diffusivity to account for transport of both types of water. Fig. 2 gives a schematic of a representative elemental volume (REV) showing how the phases are characterized in the present formulation.

Two types of volume averages are useful for porous media models; an intrinsic average, which is the averaged value of a property $\varphi$ over a specific phase volume within an REV, and an extrinsic average defined as the average value of $\varphi$ over the total volume of the REV. The expressions for both averages are, respectively, given by,

$\left\langle\varphi_{x}\right\rangle^{x}=\frac{1}{V_{x}} \int_{V_{x}} \varphi_{x} d V$
$\left\langle\varphi_{x}\right\rangle=\frac{1}{V} \int_{V_{x}} \varphi_{x} d V$

where $x$ represents the phase index, $V_{x}$ is the volume of phase $x$ within the REV and $V$ is the total volume of the REV. The following expression is also useful for linking the two averages for fluid phases,

$\left\langle\varphi_{f}\right\rangle=\varepsilon\left\langle\varphi_{f}\right\rangle^{f}$

with $\varepsilon$ indicating the porosity defined by the void volume over the total volume of the moist material. All the quantities solved for in the porous region are intrinsic averages except for the velocity as it is useful to obtain an extrinsic average to characterize the averaged fluid flow. In the absence of external forces and external heat and mass sources, the volume-averaged form of the Navier-Stokes equations for the continuity, momentum, moisture mass fractions and energy for the relevant phases are cast, respectively, as,

$$
\begin{aligned}
& \varepsilon \frac{\left\langle\partial \rho_{f}\right\rangle^{f}}{\partial t}+\nabla \cdot\left(\left\langle\rho_{f}\right\rangle^{f}\langle\mathbf{v}\rangle\right)=0 \\
& \frac{\partial\left(\left\langle\rho_{f}\right\rangle^{f}\langle\mathbf{v}\rangle\right)}{\partial t}+\frac{1}{\varepsilon} \nabla \cdot\left(\left\langle\rho_{f}\right\rangle^{f}\langle\mathbf{v}\rangle\langle\mathbf{v}\rangle\right) \\
& =-\varepsilon \nabla\langle P\rangle^{f}+\mu_{f} \nabla^{2}\langle\mathbf{v}\rangle-\frac{\varepsilon \mu_{f}}{K}\langle\mathbf{v}\rangle-\frac{\varepsilon\left\langle\rho_{f}\right\rangle^{f} c_{E}}{\sqrt{K}}|\langle\mathbf{v}\rangle|\langle\mathbf{v}\rangle \\
& \varepsilon \frac{\partial\left(\left\langle\rho_{f}\right\rangle^{f}\left\langle Y_{v f f}\right\rangle^{f}\right)}{\partial t}+\nabla \cdot\left(\left\langle\rho_{f}\right\rangle^{f} Y_{v f f}^{f}\langle\mathbf{v}\rangle\right) \\
& =\nabla \cdot\left(\left\langle\rho_{f}\right\rangle^{f} D_{e f f . f} \nabla\left\langle Y_{v, f}\right\rangle^{f}\right)+\left\langle\dot{m}_{f s}\right\rangle \\
& (1-\varepsilon) \frac{\partial\left(\left\langle\rho_{s}\right\rangle^{s}\left\langle Y_{w, s}\right\rangle^{s}\right)}{\partial t}=\nabla \cdot\left(\left\langle\rho_{s}\right\rangle^{s} D_{e f f, s} \nabla\left\langle Y_{w, s}\right\rangle^{s}\right)-\left\langle\dot{m}_{f s}\right\rangle \\
& \sum_{i} \varepsilon c_{p, i} \frac{\partial\left(\left\langle\rho_{f}\right\rangle^{f}\left\langle Y_{i, f}\right\rangle^{f}\left\langle T_{f}\right\rangle^{f}\right)}{\partial t}+\sum_{i} \varepsilon h_{f g, i} \frac{\partial\left(\left\langle\rho_{f}\right\rangle^{f}\left\langle Y_{i, f}\right\rangle^{f}\right)}{\partial t} \\
& \quad+\sum_{i} c_{p, i} \nabla \cdot\left(\left\langle\rho_{f}\right\rangle^{f}\left\langle Y_{i, f}\right\rangle^{f}\left\langle T_{f}\right\rangle^{f}\langle\mathbf{v}\rangle\right)+\sum_{i} h_{f g, i} \nabla \cdot\left(\left\langle\rho_{f}\right\rangle^{f}\left\langle Y_{i, f}\right\rangle^{f}\langle\mathbf{v}\rangle\right) \\
& =k_{e f f, f} \nabla^{2}\left\langle T_{f}\right\rangle^{f}+\sum_{i} \nabla \cdot\left[\left\langle\rho_{f}\right\rangle^{f} D_{e f f . f} \nabla\left\langle Y_{i, f}\right\rangle^{f}\left(c_{p, i}\left\langle T_{f}\right\rangle^{f}+h_{f g, i}\right)\right] \\
& \quad+h_{f s} A_{f s}\left(\left\langle T_{s}\right\rangle^{s}-\left\langle T_{f}\right\rangle^{f}\right)+\dot{H}_{f s}^{m a s s} \\
& \sum_{i}(1-\varepsilon) c_{p s, i} \frac{\partial\left(\left\langle\rho_{s}\right\rangle^{s}\left\langle Y_{i, s}\right\rangle^{s}\left\langle T_{s}\right\rangle^{s}\right)}{\partial t} \\
& =k_{e f f, s} \nabla^{2}\left\langle T_{s}\right\rangle^{s}+\sum_{i} \nabla \cdot\left[\left\langle\rho_{s}\right\rangle^{s} D_{e f f, s} \nabla\left\langle Y_{i, s}\right\rangle^{s}\left(c_{p s, i}\left\langle T_{s}\right\rangle^{s}\right)\right] \\
& \quad h_{f s} A_{f s}\left(\left\langle T_{s}\right\rangle^{s}-\left\langle T_{f}\right\rangle^{f}\right)-H_{f s}^{m a s s}
\end{aligned}
$$

The additional terms in the volume-averaged equations result from the closure of the volume-averaging process. The last two terms of the momentum equation (Eq. (11)) are the heuristic skin and form drag terms, respectively, resulting from the frictional effects on the flow in the void constituent that are filtered through the volume-averaging. The non-equilibrium approach to treating 


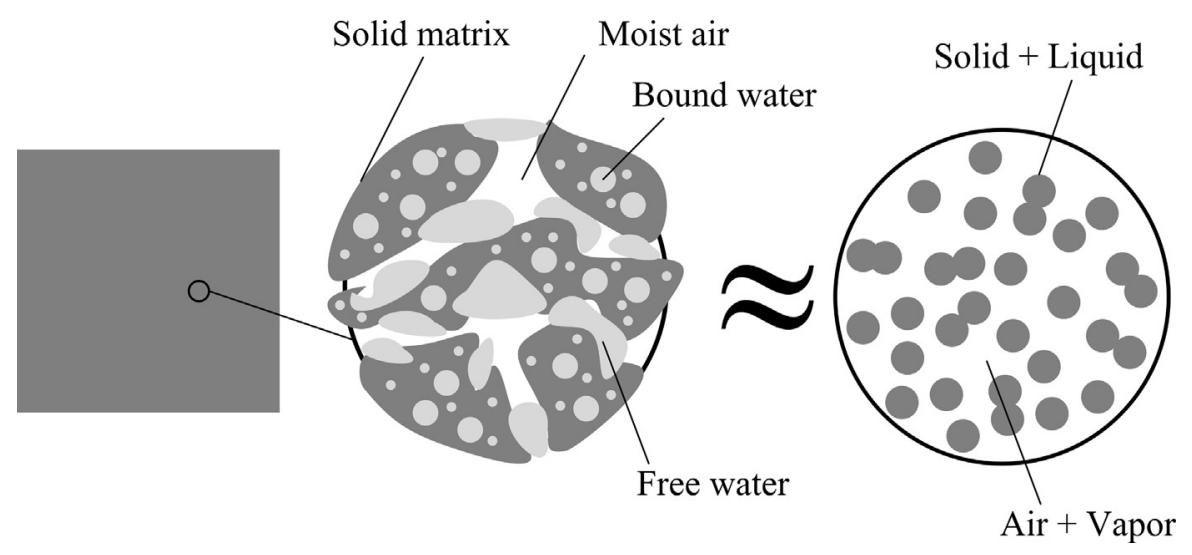

Fig. 2. Illustration showing the different constituents in the porous region and the simplification of the problem.

heat and mass transfer is achieved through the solution of two coupled phase equations for energy transfer, (Eqs. (14) and (15), and mass transfer, (i.e. vapor mass fraction equation for the fluid constituent and liquid mass fraction equation for the solid constituent; Eqs. (12) and (13). The terms $h_{f s} A_{f s}\left(\left\langle T_{s}\right\rangle^{s}-\left\langle T_{f}\right\rangle^{f}\right),\left\langle\dot{m}_{f s}\right\rangle$ and $\dot{H}_{f s}^{\text {mass }}$ are the heat and mass transfer closure terms that require careful consideration for dynamic coupling. The first term represents the convective interfacial heat transfer term between the fluid and solid phase of the porous region. This convective coefficient $h_{f s}$ is evaluated using a local empirical heat transfer correlation as it is only a function of the fluid mixture properties, the fluid flow, and the internal geometry of the porous material. This term is not dynamic in nature and is present with the same form as in non-masstransfer problems [36]. $\left\langle\dot{m}_{f s}\right\rangle$ is the local interfacial mass exchange term representing the mass flux exchanged between the moist solid and fluid mixture phases (see Fig. 2). This term is dynamically varying and will be discussed extensively in subsequent sections. $\dot{H}_{f s}^{\text {mass }}$ is the interfacial closure term that is analogous to the species energy diffusion term. It represents the heat exchanged between the phases accompanying mass exchange. It is also dynamically varying and is related to the source of the vaporization energy and the apportioning of this energy on the different phases. This term will also be discussed in subsequent sections. It is also worth mentioning that the effective conductivities and mass diffusivities in the heat and mass transfer transport equations are considered porous material properties that are functions of the nature of the heat and mass transfer processes. They represent effects of the transport phenomena (i.e. whether diffusive, capillary or surface tension effects) microscopically and are scaled-up through the volume-averaging process. They also represent dispersion and tortuosity effects and are often functions of moisture content and temperature. It is noted here however, that existing studies contain a great deal of empiricism when they handle these coefficients. It is noted that experiments are required to accurately estimate these properties at the microscopic level at different conditions, so that pore level simulations may be effectively used to arrive at the correct volume-averaged values for these effective properties.

Another aspect to highlight is the fact that the closure mass exchange source term is absent from the continuity equation. The present formulation utilizes a unique discretization approach that allows for the update of the mixture density within each time step for the continuity, momentum and energy equations, while it explicitly includes a source term in the mass transfer equations. This technique was described in the work of Khan et al. [25] and also resulted in the absence of the $\dot{H}_{f s}^{\text {mass }}$ source term from their formulation, as the total vaporization energy was apportioned to the void constituent of the porous material. While this assumption is not an issue for evaporative cooling cases, it is relatively inaccurate for cases with high temperature gradients. A solution for this issue will be presented in subsequent sections. Another difference from Khan et al. [25] is in regards to the liquid mass fraction $\left\langle Y_{w, s}\right\rangle^{s}$. Herein, we define the liquid mass fraction on a dry basis, as opposed to a wet basis, so that $\left\langle Y_{s, s}\right\rangle^{s}=1$, and the solid density $\left\langle\rho_{s}\right\rangle^{s}$ is a constant value, which removes a non-linearity in the computational solution that is no longer required. By this approach, the level of water saturation of the porous material is not required to be specified in the formulation, unlike the work of Khan and Straatman [9], as they specified their solid matrix to be volume-saturated with water at the start of drying, which is not necessarily true.

\subsection{Macroscopic interface conditions}

Interface conditions are required to robustly and accurately couple the transport equations in the pure fluid and porous regions. They also ensure the smoothness and continuity of solved quantities across interfaces. The interface conditions take into account the different nature of the point equation on the fluid side compared to the volume-averaged equation on the porous side. The conditions for the fluid flow and pressure are cast as:

$\mathbf{v}_{f l}=\langle\mathbf{v}\rangle_{\text {por }}$

$P_{f l}=\langle P\rangle_{\text {por }}^{f}$

in which the extrinsic velocity and intrinsic pressure are continuous (see reference [37] for specifics). The fluxes of mass transfer have to match as well, i.e. the sum of the (liquid and vapor) diffusive mass fluxes leaving/entering on the porous side has to be continuous with the entering/leaving vapor flux on the fluid side. This is expressed mathematically as,

$$
\left(-\rho_{f} D_{f} \frac{\partial Y_{v}}{\partial \boldsymbol{n}}\right)_{f l}=\left(-\left\langle\rho_{f}\right\rangle^{f} D_{e f f . f} \frac{\partial\left\langle Y_{v f f}\right\rangle^{f}}{\partial \boldsymbol{n}}-\left\langle\rho_{s}\right\rangle^{s} D_{e f f, s} \frac{\partial\left\langle Y_{w, s}\right\rangle^{s}}{\partial \boldsymbol{n}}\right)_{p o r}
$$

For a combined heat and mass transfer problem, the macroscopic interface condition is different from that described by Betchen et al. [37]. In this case, the sum of both sensible and latent fluxes must be in balance, and this is expressed as,

$$
\begin{aligned}
\left(-k_{f}\left(\frac{\partial T}{\partial \boldsymbol{n}}\right)-\sum_{i}\left[\rho_{f} D_{f}\left(\frac{\partial Y_{i}}{\partial \boldsymbol{n}}\right)\left(c_{p, i} T+h_{f g, i}\right)\right]\right)_{f l} \\
=\left(-k_{\text {eff } f} \frac{\partial\left\langle T_{f}\right\rangle^{f}}{\partial \boldsymbol{n}}-\sum_{i}\left[\left\langle\rho_{f}\right\rangle^{f} D_{e f f, f}\left(\frac{\partial\left\langle Y_{i, f}\right\rangle^{f}}{\partial \boldsymbol{n}}\right)\left(c_{p, i}\left\langle T_{f}\right\rangle^{f}+h_{f g, i}\right)\right]\right. \\
\left.\quad-k_{\text {eff }, s} \frac{\partial T_{s}^{s}}{\partial \boldsymbol{n}}-\sum_{i}\left[\rho_{s}^{s} D_{e f f, s}\left(\frac{\partial Y_{i, s}^{s}}{\partial \boldsymbol{n}}\right)\left(c_{p s, i}\left\langle T_{s}\right\rangle^{s}\right)\right]\right)_{p o r}
\end{aligned}
$$


Eqs. (16)-(19) represent the mathematical conditions of the conjugate coupling across macroscopic interfaces. The actual implementation and discretization selected to achieve these conditions is presented in detail for the hydrodynamics by Betchen et al. [37]. In regards to heat and mass transfer, a discussion will follow in a subsequent section.

\section{Dynamic coupling models}

Now that the formulation of the conjugate problem is presented along with a means for coupling regions across interfaces, the task turns to formulating physics-based dynamic models that account for mass and energy transfers at microscopic (interstitial) and macroscopic interfaces. As noted in Section 2, the terms that require specific attention are the mass exchange terms and their associated vaporization energy terms. In the subsections to follow, models are formed for these terms at microscopic and macroscopic interfaces that, when combined with the formulation of Section 2, yield a complete non-equilibrium heat and mass transfer model that can be used for a variety of drying processes.

\subsection{Coupling of phase heat and mass transfer at microscopic interfaces}

When one considers the mass exchange term, a first choice and a seemingly reasonable form for this term would be a mass transfer analogue for Newton's law of cooling, as given by Khan et al. [25],

$\left\langle\dot{m}_{f s}\right\rangle=\left\langle\rho_{f}\right\rangle^{f} h_{f s m} A_{f s}\left(\left\langle Y_{v}\right\rangle^{f_{s}}-\left\langle Y_{v f}\right\rangle^{f}\right)$

where $h_{f s m}$ is a convective mass transfer coefficient that is obtained from an empirical correlation of mass transfer based on the characteristics of the flow and the geometry of the porous material and $\left\langle Y_{v}\right\rangle^{f_{s}}$ is the surface fluid mass fraction (assumed at 100\% relative humidity in the work of Khan et al. [25]). The above expression is suitable whenever the moist solid has sufficient liquid water present, however if drying out is imminent, either the expression is not suitable or it has to be empirically adjusted [25]. Eq. (20) is also based on pure diffusion through the mass transfer boundary layer and does not consider an advective flux near the solid surface which, in cases where advective effects are considerable, will compromise the accuracy. The physics of the mass transfer process indicates the existence of two main resistances. The first is an internal resistance from the core of the solid to the microscopic interface. This resistance becomes important when the moist material gets relatively dry, meaning the solid constituent supply of moisture becomes less than the air side capacity for moisture withdrawal. The second resistance is on the air side as the surface vapor diffuses and is advected to the air stream. Phase change is considered to occur at the microscopic interface and is assumed not to interplay with these resistances. Furthermore, the higher of these two described resistances is considered rate-determining. To develop an air side resistance expression, we assume the solid portion of the porous medium to consist of uniform sized spherical particles (see Fig. 2). These particles are analogous to spray droplets in an air stream [38] when we consider mass transfer.

Fig. 3 shows a schematic of a spherical solid showing the profiles of liquid and vapor mass fraction in the solid and moist air. If we consider the thin vapor mass fraction diffusion layer using a quasi-steady, one dimensional (i.e. radial) diffusion point equation, then taking both advection and diffusion into consideration [38], we obtain,

$\left\langle\dot{m}_{f s}\right\rangle=\left\langle\rho_{f}\right\rangle^{f} h_{f s m} A_{f s} \ln \left(\frac{1-\left\langle Y_{v f}\right\rangle^{f}}{1-\left\langle Y_{v}\right\rangle^{f s}}\right)$

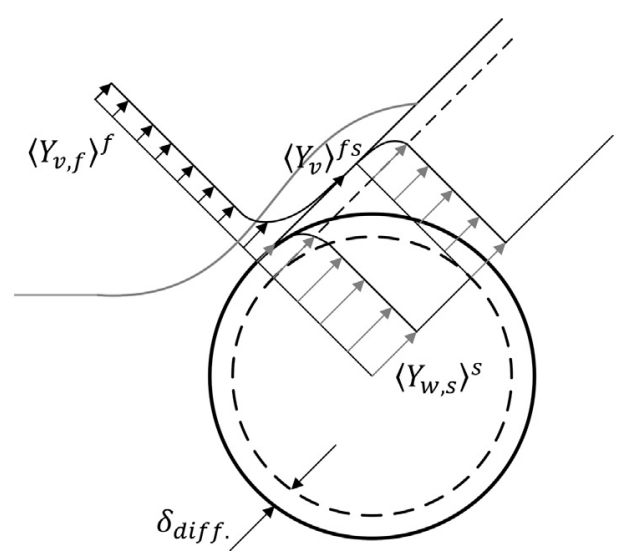

Fig. 3. Schematic showing a spherical solid holding liquid water within its micropores subjected to a stream of moist air.

Or, in the interest of implicit implementation and convergence control, we cast Eq. (21) as,

$\left\langle\dot{m}_{f s}\right\rangle=\left\langle\rho_{f}\right\rangle^{f} h_{f s m} A_{f s} \frac{\ln (1+B)}{B}\left(\frac{\left\langle Y_{v}\right\rangle^{f s}-\left\langle Y_{v f}\right\rangle^{f}}{1-\left\langle Y_{v}\right\rangle^{f s}}\right)$

where $B$ is the local Spalding mass transfer number, defined by $\left(\left\langle Y_{v}\right\rangle^{f_{s}}-\left\langle Y_{v f f}\right\rangle^{f}\right) /\left(1-\left\langle Y_{v}\right\rangle^{f_{s}}\right)$. Another change we introduce is in regards to the surface vapor mass fraction. To prolong the validity of Eq. (22) as the material loses moisture with time, we introduce the deviation from surface vapor saturation using the water activity concept. It has been mentioned earlier that the water activity is an application of the thermodynamic equilibrium for the moist material; it introduces a relation between the liquid water mass fraction $\left\langle Y_{w, s}\right\rangle^{s}$ and the solid surface vapor relative humidity (i.e. water activity) that is based on an equal chemical potential for both phases [6]. This relation is often referred to as the sorption isotherm, as it is different for different surface temperatures. Based on this approximation, the surface vapor mass fraction is defined as,

$\left\langle Y_{v}\right\rangle^{f_{s}}=\frac{a_{w} P_{\text {sat. }}}{\left\langle\rho_{f}\right\rangle^{f} R_{v}\left\langle T_{s}\right\rangle^{s}}$

with $a_{w}$ representing the water activity and $P_{\text {sat }}$ calculated at the particle surface temperature. Eq. (22) is valid as long as the thermodynamic equilibrium assumption is valid. If the solid side resistance is rate-determining, the expression will not be accurate. In this case, as drying out becomes imminent, the surface of the solid becomes almost dry and the moisture is mostly embedded in the core of the solid constituent, which violates the thermodynamic equilibrium assumption, since the present formulation does not include the effect of shrinkage. Given that the process of liquid diffusion in the solid constituent is assigned an effective diffusivity $D_{\text {eff }, s}$, it is physically reasonable to assume a significant diffusion thickness within the solid particle, in which the significant part of the liquid concentration difference occurs based on this effective diffusivity; a concept that is analogous to the one widely used in the lumped conduction models [39]. Usually lumped conduction models have a strong dependence on the order of the transient. In the present model however this dependence on the transient can impose time step restrictions. Thus, instead of the lumped diffusion approach, we estimate a significant diffusion thickness using the concept of the volume-averaging. Since the boundary layer thickness on the vapor side is considered of a length scale that is small enough not to violate a fixed volume averaged quantity throughout the fluid volume in a CFD cell, the significant diffusion thickness $\delta_{\text {diff. }}$ is reasonable to be of the same order of magnitude, but with respect to 
the solid volume. If we assume that the ratio of length scales associated with both resistances is proportional to the phase volume ratio then,

$\delta_{\text {diff. }}=\frac{d_{p}}{S h}\left(\frac{1-\varepsilon}{\varepsilon}\right)^{1 / 3}$

with $\left(d_{p} / S h\right)$ representing that ratio of the average particle diameter over the local Sherwood mass transfer number; i.e. the vapor mass transfer boundary layer thickness. Then, based on Eq. (24), the solid side mass exchange expression can be cast as,

$\left\langle\dot{m}_{f s}\right\rangle=\left\langle\rho_{s}\right\rangle^{s} \frac{D_{\text {eff.s }}}{\delta_{\text {diff. }}} A_{f s}\left(\left\langle Y_{w, s}\right\rangle^{s}-\left\langle Y_{w, s}\right\rangle^{f s}\right)$

For the solid side resistance to be dominant, the surface liquid fraction $\left\langle Y_{w, s}\right\rangle^{f_{s}}$ must be negligible. A check is performed locally within the non-linear CFD loop on whether the mass transfer by Eqs. (22) or (25) is lower in value and the lower value is implemented implicitly. When Eq. (25) is utilized, we equate the expression given by Eqs. (20)-(25), and obtain a mass transfer coefficient that is smoothly declining as a function of $\left\langle Y_{w, s}\right\rangle^{s}$. The implicit technique of implementation ensures smooth convergence.

Now we turn our attention to the energy exchange closure term, $\dot{H}_{f s}^{\text {mass }}$. This term basically accounts for the addition/subtraction of enthalpy due to the mass flux entering/exiting each of the phase volumes. In this respect, the moisture mass either leaves the solid phase as a liquid - i.e. indicating it takes its vaporization energy from the fluid constituent - or it leaves as a vapor, withdrawing its vaporization energy from the solid constituent. In evaporative cooling applications [25], the former approximation could be selected, while for materials that are highly resistive to liquid diffusion and involve a significant difference between solid and fluid constituents' temperature - i.e. significant thermal nonequilibrium - the latter approximation is usually selected (an observation that is made for most of the particle and grain drying studies $[27,30,32])$. Both approximations, however, introduce a loss of generality as both phases participate in the evaporation process [34]. To obtain a general expression for the energy of mass exchange, we assume that the shares of the vaporization energy are closely correlated to the heat transfer, i.e. conductive/advective resistances for both phases. We consider the local Biot number defined as,

$B i=\frac{h_{f s}\left(\frac{d_{p}}{N u}\left(\frac{1-\varepsilon}{\varepsilon}\right)^{\frac{1}{3}}\right)}{k_{\text {eff }, s}}$

noting that we estimate the length scale of solid conduction by a local Nusselt number $(\mathrm{Nu})$ in a manner similar to Eq. (24). Since this local Biot number represents the ratio between the resistances of solid conduction to the outside fluid convection, we use it to define a proportioning factor $\alpha$, where this factor represents the fraction of the vaporization energy that the solid constituent contributes. Assuming that solid-to-fluid ratio of the share of mass transfer energy is proportional to the inverse ratio of heat resistances, we define the proportioning factor as,

$\alpha=\frac{1}{B i+1}$

Based on this proportioning factor $\alpha$, the heat transfer exchange term is defined as,

$\dot{H}_{f s}^{\text {mass }}=\left\langle\dot{m}_{f s}\right\rangle\left[\alpha h_{v}\left(\left\langle T_{s}\right\rangle^{s}\right)+(1-\alpha) h_{l}\left(\left\langle T_{s}\right\rangle^{s}\right)\right]$

where $h_{v}$ and $h_{l}$ are the vapor and liquid specific enthalpies evaluated at the surface particle temperature. This apportioning process is valid when the surface of the solid constituent is relatively wet. For cases when Eq. (25) is used, the surface of the solid is assumed dry and hence the outer fluid region is assumed not to be in contact with the liquid embedded in the core of the solid constituent. In this case $\alpha=1$, indicating that all of the vaporization energy is obtained from the solid constituent. In Eq. (28), $h_{v}$ and $h_{l}$ are absolute enthalpies referenced at absolute zero temperature. Specific heats of liquid and vapor moistures, referenced at $0 \mathrm{~K}$ are used for this purpose as adopted from Pakowski et al. [40]. To perform the proportioning described here within the context of the unique discretization approach used in Khan et al. [25], the term $\left\langle\dot{m}_{f s}\right\rangle h_{v}\left(\left\langle T_{f}\right\rangle^{f}\right)$ is added explicitly to the source term in the fluid temperature energy equation in the porous region.

\subsection{Coupling of heat and mass transfer at macroscopic interfaces}

The present subsection introduces an approach for practical implementation of the mathematical conditions that were presented in Section 2.3. The main focus is directed at coupling the fluid side equation to the two non-equilibrium equations on the porous side for heat and mass transfer. If we idealize the interface condition to be one dimensional, following on the work of Betchen et al. [37] and Khan et al. [25], we are able to produce moisture and temperature circuit analogues for mass and heat transfer exchange processes, respectively. First, we consider the moisture exchange circuit illustrated in Fig. 4, which shows a clear fluid cell (P) with a porous cell (E) adjacent to its east face, separated by face 'e'. The diffusion mass fluxes obtained from the defined resistances are implemented implicitly, as the in-house code solves both regions and both equations simultaneously. Five resistances are introduced: $R_{v 1_{f}}$ and $R_{v_{f}}$ represent the fluid leg resistances that link the nodal fluid vapor mass fractions. $R_{v 2_{s}}, R_{f-s}$ and $R_{W_{s}}$ are the solid leg resistances that link the porous node's solid phase liquid fraction to the fluid node's vapor fraction. The fluid leg of the resistance is straightforward and is treated using a technique similar to Khan et al [25], where the relevant resistances are defined as,

$R_{v 1_{f}}=\frac{\Delta x_{P e}}{\rho_{f_{P}} \varepsilon A_{e} D_{f}}$
$R_{v_{f}}=\frac{\Delta x_{e E}}{\left\langle\rho_{f}\right\rangle_{E}^{f} A_{e} D_{\text {eff. } f}}$

Using the harmonic mean formulation [37] to couple the two cells, we obtain,

$\dot{m}_{v_{f}}=\frac{\left\langle Y_{v f}\right\rangle_{E}^{f}-Y_{v_{p}}}{R_{v 1_{f}}+R_{v_{f}}}$

Now, we shift attention to the solid leg of the resistance, which requires consideration of two factors: the dynamic nature of the variation in its resistances which vary strongly in space and time

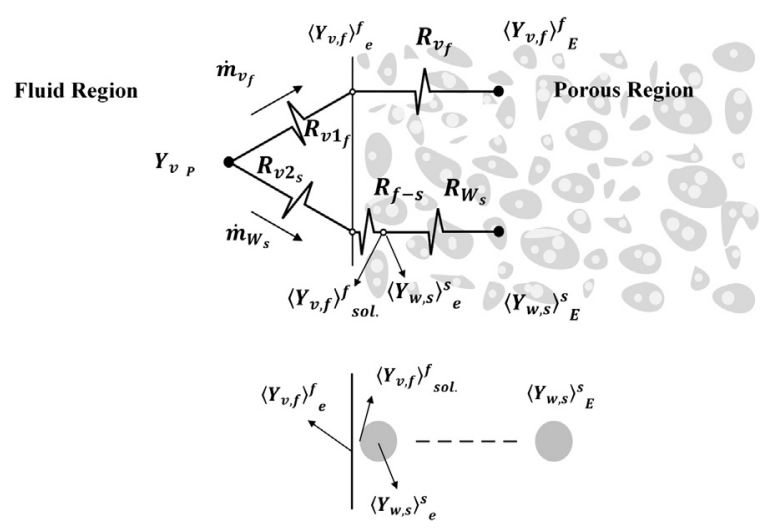

Fig. 4. Moisture circuit analogue at the macroscopic interface. 
and necessitate a strong and implicit form of coupling; and, the fact that the two nodal values are for different quantities, i.e. liquid and vapor fractions. The driving potential difference for mass exchange in this case has to be consistent with both sides and representative of the physical transport occurring. A technique for achieving these requirements is presented here. Two modes of mass transfer are considered. In the first mode, the surface of the solid constituent at the macroscopic interface is considered wet, meaning that the liquid availability is high enough so that the clear fluid side capacity to entrain vapor is the controlling factor for mass transfer. Usually as the convective flow moves across and through the moist material, this capacity remains relatively unchanged on the fluid side as the fluid is renewable and hence, in the literature this mode of mass transfer is referred to as the Constant drying rate period $[5,7,8]$. In the present paper, without loss of generality, we introduce the term Convectively dominant for this mode. Referring to Fig. 4, consider a spherical solid that is the closest to the fluid/porous interface between cells $\mathrm{P}$ and $\mathrm{E}$. The liquid moisture mass fraction inside of this spherical solid is $\left\langle Y_{w, s}\right\rangle_{e}^{s}$ and has the value of the liquid moisture presence based on the diffusion resistance within half the control-volume at $\mathrm{E}$. The surface vapor fraction of this spherical solid $\left\langle Y_{v f}\right\rangle_{\text {sol. }}^{f}$, is then obtained using Eq. (23) since the surface is considered wet in this mode of mass transfer. Utilizing the same vapor moisture boundary layer concept developed in Section 3.1, Eq. (22) may be used with a driving potential difference $\left(\left\langle Y_{v f f}\right\rangle_{\text {sol. }}^{f}-\left\langle Y_{v f}\right\rangle_{e}^{f}\right)$ and an area $A_{e}(1-\varepsilon)$ to characterize the mass transport between this spherical solid and the clear fluid side. An interface Spalding mass transfer number $B_{\text {interf. }}$ is defined based on the same potential difference, and an interface Sherwood number $S h_{\text {interf. }}$ is utilized to obtain the mass transfer coefficient. The same empirical correlation that is used interstitially is used for $S h_{\text {interf. }}$, however the magnitude of the velocity calculated to arrive at the interface Reynolds number is estimated at the interface based on cell (E)'s two transverse extrinsic velocities and the axial interface intrinsic velocity. Using the above approximations, the solid leg resistances are,

$$
\begin{aligned}
R_{v 2_{s}} & =\frac{\Delta x_{P e}}{\rho_{f_{P}}(1-\varepsilon) A_{e} D_{f}} \\
R_{f-s} & =\frac{d_{P} B_{\text {interf. }}\left(1-\left\langle Y_{v f}\right\rangle_{\text {sol. }}^{f}\right)}{\rho_{f_{P}}(1-\varepsilon) A_{e} D_{f} S h_{\text {interf. }} \ln \left(1+B_{\text {interf. }}\right)} \\
R_{W_{s}} & =\frac{\Delta x_{e E}}{\left\langle\rho_{s}\right\rangle_{E}^{s} A_{e} D_{\text {eff }, s}}
\end{aligned}
$$

One can then obtain the following expression for the mass flux:

$$
\begin{aligned}
\dot{m}_{W_{s}}= & \frac{\rho_{f_{P}}(1-\varepsilon) D_{f} A_{e}\left(\left\langle Y_{v f f}\right\rangle_{\text {sol. }}^{f}-Y_{v_{P}}\right)}{\Delta x_{P e}+\frac{d_{P} B_{\text {interf. }}\left(1-\left\langle Y_{v f f}\right\rangle_{\text {sol. }}^{f}\right)}{S h_{\text {interf. }} \cdot \ln \left(1+B_{\text {interf. }}\right)}} \\
= & \frac{\left\langle\rho_{S}\right\rangle_{E}^{S} D_{e f f_{s}} A_{e}\left(\left\langle Y_{w, S}\right\rangle_{E}^{S}-\left\langle Y_{w, S}\right\rangle_{e}^{S}\right)}{\Delta x_{e E}}
\end{aligned}
$$

Eq. (32) achieves the required physical transport, but is not useful for coupling. In order to achieve the implicit coupling, we have to define a single value for the moisture driving potential at the interface that is compatible with both sides so that it is possible to ensure the continuity of the flux across the interface by utilizing the harmonic mean formulation. The concept of the equilibrium ratio, developed by Whitman [41], was useful in that sense. However, unlike the equilibrium ratio between the two phases' concentrations in his two liquid films, the phase ratio we define here is not of fixed value. It is non-linearly varying in space and time. Instead of developing a ratio between both liquid and vapor mass fractions, the phase ratio $(\mathrm{K})$ is defined herein as,
$\mathrm{K}=\frac{\left\langle\rho_{s}\right\rangle_{E}^{s} D_{e f f, s}\left\langle Y_{w, s}\right\rangle_{e}^{s}}{\rho_{f_{P}}(1-\varepsilon) D_{f}\left\langle Y_{v, f}\right\rangle_{\text {sol. }}^{f}}$

The ratio is dimensionless and is selected to include densities and diffusivities as a means for controlling its order of magnitude and variation. Using the harmonic mean formulation [37], Eq. (32) can now be recast as,

$$
\left.\dot{m}_{W_{s}}=\frac{A_{e}\left(\left\langle\rho_{s}\right\rangle_{E}^{S} D_{e f f, s}\left\langle Y_{w, S}\right\rangle_{E}^{S}-\mathrm{K} \rho_{f_{P}}(1-\varepsilon) D_{f} Y_{v_{P}}\right)}{\mathrm{K}\left(\Delta x_{P e}+\frac{d_{P} B_{\text {interf. }}\left(1-\left\langle Y_{v f f}\right\rangle_{\text {sol. }}\right)}{S_{\text {interf. }} .}\right)+\Delta x_{e E}\left(1+B_{\text {interf }} .\right)}\right)+\Delta
$$

which is implemented implicitly. The ratio $\mathrm{K}$ is locally available for convectively dominant cases, since Eqs. (23) and (32) make the calculation of $\left\langle Y_{v f f}\right\rangle_{\text {sol. }}^{f}$ and $\left\langle Y_{w, S}\right\rangle_{e}^{S}$ straightforward.

In the second mode of mass transfer, the surface of the solid constituent at the fluid/porous interface is considered dry; i.e. the delivered mass flux from the solid side is lower than the air side capacity to withdraw vapor moisture so that the solid side transport of liquid is the controlling factor. Since the ability to transport moisture depends on the amount of moisture present, this case is referred to in the literature as the Falling drying rate period $[5,7,8]$, which we refer to as Diffusively dominant. A dry interface leads to the presence of a traveling liquid moisture front that shrinks inside the porous material and develops a dry layer of porous material at the interface rendering the mechanism of mass transport as mainly vapor diffusion [8]. In a non-volumeaveraged porous domain, the dry layer thickness will increase significantly with time as the substance dries up. However, in the present formulation we use a single value for liquid mass fraction to characterise the whole control volume and hence, to satisfy the concept of volume-averaging, this thickness has to be small enough and compatible with the microscopic scales of the volume-averaging process such that the values of the volumeaveraged liquid mass fraction for the porous cells adjacent to the macroscopic interface are representative of the moisture present. Thus, we assume the dry layer thickness to be of the same order of magnitude as the drying boundary layer thickness. The interface resistance network shown in Fig. 4 is also used to represent diffusively dominant cases. For this case, the dry layer resistance is $R_{f-s}$. The main solid leg circuit resistances $R_{v 2_{s}}$ and $R_{W_{s}}$ have the same definition as in Eq. 31, while the dry layer resistance is modified to,

$R_{f-s}=\frac{d_{p} / S h_{\text {interf. }}}{\rho_{f_{p}}(1-\varepsilon) A_{e} D_{f}}$

Based on Eq. (35), the solid leg mass flux for diffusively dominant cases is then given by,

$\dot{m}_{W_{s}}=\frac{A_{e}\left(\left\langle\rho_{S}\right\rangle_{E}^{S} D_{e f f, s}\left\langle Y_{w, S}\right\rangle_{E}^{S}-\mathrm{K} \rho_{f_{P}}(1-\varepsilon) D_{f} Y_{v_{P}}\right)}{\mathrm{K}\left(\Delta x_{P e}+\frac{d_{P}}{S h_{\text {interf. }}}\right)+\Delta x_{e E}}$

Thus, while Eq. (33) still represents the phase ratio in the diffusively dominant mode, as the surface of the solid constituent becomes dry, the $\left\langle Y_{v f}\right\rangle_{\text {sol. }}^{f}$ is no longer valid as estimated by Eq. (23). Moreover, $\left\langle Y_{w, S}\right\rangle_{e}^{S}$ is no longer available. Since we assume the liquid mass fraction to be negligible at the interface, the following equation representing an estimate of the mass transfer at the dry layer can be cast as,

$\rho_{f_{p}}(1-\varepsilon) D_{f}\left(\left\langle Y_{v f f}\right\rangle_{\text {sol. }}^{f}-\left\langle Y_{v f f}\right\rangle_{e}^{f}\right)=\left\langle\rho_{S}\right\rangle_{E}^{S} D_{e f f, s}\left\langle Y_{w, s}\right\rangle_{e}^{S}$

After inserting Eq. (33) into Eq. (37), we arrive at,

$\mathrm{K}=1-\frac{1}{1+\frac{\left\langle\rho_{s}\right\rangle_{E}^{s} D_{e f f, s}\left\langle Y_{w, s}\right\rangle_{e}^{s}}{\rho_{f_{p}}(1-\varepsilon) D_{f}\left\langle Y_{v, f}\right\rangle_{e}^{j}}}$ 
In the solution procedure, the ratio $\left\langle Y_{w, s}\right\rangle_{e}^{s} /\left\langle Y_{\nu, f}\right\rangle_{e}^{f}$ is estimated explicitly from the solution of the previous time step, since extrapolation of either of the mass fraction values independently could artificially increase the importance of one side's resistance over the other side.

To determine the mode of mass transfer of the problem, a check based on Eq. (32) is performed locally at every time step before calculating the values of any of the solid leg resistances. The check sets $\left\langle Y_{w, s}\right\rangle_{e}^{s}$ to zero and considers the interface convectively dominant if the left hand side is lower than the right, and diffusively dominant otherwise.

We now turn our attention to the energy exchange closure term, $\dot{H}_{f s}^{\text {mass }}$, at the macroscopic interface. Recall that Eq. (19) represents the mathematical condition of heat transfer at the interface. In a manner similar to the notion that the pressure and normal stresses at the interface balance separately on each side instead of their sum [37], we assume that the conduction and the species diffusive energy terms also balance separately. The conduction terms are set in balance using the approach presented in Betchen et al. [37] and is implemented implicitly. The fluid species diffusion energy balance between the clear fluid and the fluid portion of the porous cell is implemented explicitly as source terms in the discrete transport equations and is represented through the species diffusion energy term in Eqs. (6) and (14). The solid portion of the porous cell to the clear fluid cell's species diffusion energy balance is expressed as,

$\dot{H}_{f_{s_{\text {macro. }}}^{\text {mass }}}=\left\|\dot{m}_{W_{s}} \cdot h_{f_{s_{\text {macro. }}}^{S}}\right\| \cdot \boldsymbol{n}=\left\|\dot{m}_{W_{s}} \cdot h_{f s_{\text {macro. }}}^{f}\right\| \cdot \boldsymbol{n}$

where $\dot{H}_{f_{s_{\text {macro }}} \text { mass }}$ represents the energy source/sink that is explicitly added/subtracted from the solid portion of the porous cell and subtracted/added to the clear fluid cell. $h_{f_{s_{\text {macro }}}}^{S}$ and $h_{f_{s_{\text {macro }}}}^{f}$ are the interface values for the specific enthalpy at the solid and fluid sides, respectively. To determine the value for these enthalpies, we follow an approach that is analogous to Eqs. (26)-(28) for the apportioning of vaporization energy between the phases on the solid side leg of the species energy exchange. Defining an interface Biot number and an interface proportioning factor as,

$B i_{\text {interf. }}=\frac{(1-\varepsilon) k_{f}}{k_{\text {eff }, s}}$

$\alpha_{\text {interf. }}=\frac{1}{B i_{\text {interf. }}+1}$

and following on with the same reasoning as for the microscopic interface, we obtain,

$\dot{H}_{f_{s_{\text {macro. }}}^{\text {mass }}}=\dot{m}_{W_{s}}\left[\alpha_{\text {interf. }} . h_{v}\left(\left\langle T_{s}\right\rangle_{e}^{s}\right)+\left(1-\alpha_{\text {interf. }}\right) h_{l}\left(\left\langle T_{s}\right\rangle_{e}^{s}\right)\right]$

which is utilised for convectively dominated transport. For diffusively dominated transport $\alpha_{\text {interf. }}=1$. The interface solid temperature value is evaluated using the harmonic mean formulation. We also add the term $\dot{m}_{W_{s}} h_{v}\left(T_{P}\right)$ explicitly in the energy equation in the fluid cell adjacent to the interface to be consistent with the unique discretization approach used in Khan et al. [25].

\section{Verification of heat/mass transfer formulation}

The models described in Section 3 are implemented into the in-house conjugate CFD code described in [25]. Cases have been chosen to demonstrate the viability of the dynamic coupling formulation across a wide range of drying applications. Note once again that the key feature of the present approach is that the microscopic and macroscopic interface treatments are selfadjusting in response to physical changes that occur during the process such that no adhoc coefficients require adjustment from case to case. It is shown in the following cases that an expression is required to characterize the dependence of $D_{\text {eff,s }}$ with respect to moisture and temperature; a relationship that could be provided experimentally. The verification considers drying of a bed of coal particles, which focuses on heat and mass exchanges inside the porous bed without the presence of a macroscopic interface. Cases are then presented to demonstrate the efficacy of the formulation in diffusively-dominant and convectively-dominant drying modes by considering conjugate domain cases with microscopic and macroscopic interfaces. All simulations were run serially using a single $2.4 \mathrm{GHz}$ Intel ${ }^{\circledR}$ Core $^{\mathrm{TM}}$ i7 processor with $6 \mathrm{~GB}$ of RAM.

\subsection{Hot air drying of a packed bed of coal particles}

The microscopic interface treatment inside the porous region is validated using a study of coal packed-bed particle drying (Stakić and Tsotsas [33]), which is depicted in Fig. 5. For this case, air flowing at $1 \mathrm{~m} / \mathrm{s}$, with 0.008 specific humidity and $100^{\circ} \mathrm{C}$ enters the bottom of a vertical cylindrical bed containing coal particles at $20{ }^{\circ} \mathrm{C}$ and $\left\langle Y_{w, S}\right\rangle_{\text {init. }}^{S}=0.423 \mathrm{~kg} / \mathrm{kg}$ dry solid. A distributor is mounted at the bed inlet so that the inlet velocity profile can be assumed uniform. The distributor also prevents back conduction and diffusion making possible the exclusion of macroscopic interfaces in the problem. The bed is cylindrical and the walls are considered insulated. Making use of axisymmetry, the two dimensional half of the bed is simulated with one side as a symmetry boundary condition and the other side as a heat and mass insulated wall. The domain consists of structured cartesian elements with mesh refinement at the cylinder wall $(y=D / 2)$. After grid and temporal convergence testing, a mesh of $25 \times 25 \times 1$ and a time step of 5 seconds were utilised. This yielded overall heat and mass transfer results that were grid-independent to better than $0.1 \%$, and smoothly varying profiles within the domain. A typical simulation of this case required approximately 8 minutes of wall-clock time. Table 1 shows the relevant information for the simulations, where most properties are obtained from Stakić and Tsotsas [33]. The permeability is evaluated using the Ergun equation [42] and the specific interfacial surface area is evaluated as 6 $(1-\varepsilon) / d_{P}$. The Forchheimer coefficient $c_{E}$ and fluid effective diffusivity $D_{\text {eff. } f}$ were obtained from Khan et al. [25]. $D_{\text {eff.f }}$ was not assumed to vary because the porosity is relatively high and hence, capillary and other effects that contribute to the change in the fluid diffusivity can be neglected.

Boundary conditions are imposed as follows: on the inlet $(x=0)$ plane, the velocity was set to $(u, v, w)=(1,0,0) \mathrm{m} / \mathrm{s}$, pressure extrapolated from inside the domain, and temperature and specific humidity at $100^{\circ} \mathrm{C}$ and 0.008 , respectively; at the outlet $(x=h)$

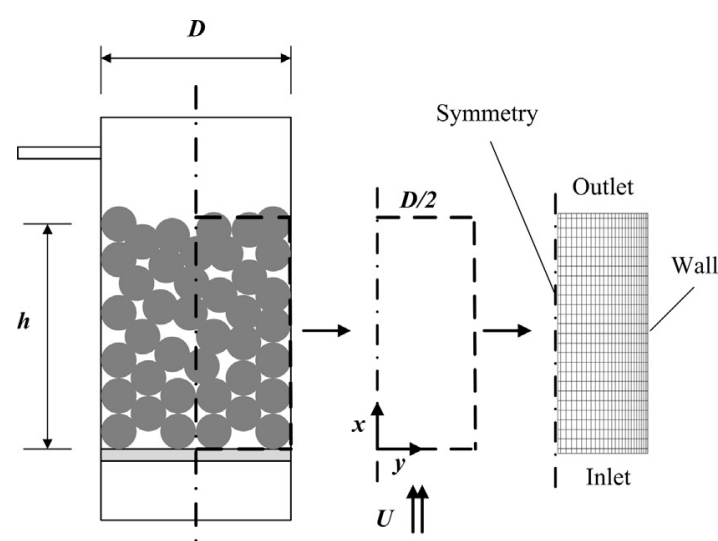

Fig. 5. A schematic of the Coal packed bed and simulation setup. 
Table 1

Coal particles properties [33,25].

\begin{tabular}{|c|c|c|c|}
\hline$h(\mathrm{~m})$ & 0.2 & Dry solid specific heat, $c_{p s}(\mathrm{~kJ} / \mathrm{kg} \mathrm{K})$ & 1.55 \\
\hline$D(\mathrm{~m})$ & 0.15 & Specific interfacial area, $A_{f s}\left(\mathrm{~m}^{-1}\right)$ & 125.2 \\
\hline Porosity, $\varepsilon$ & 0.52 & Average particle diameter, $d_{p}(\mathrm{~m})$ & 0.023 \\
\hline Permeability, $K\left(\mathrm{~m}^{2}\right)$ & $2.152 \times 10^{-6}$ & Solid effective thermal conductivity, $k_{\text {eff } s}(\mathrm{~W} / \mathrm{m} \mathrm{K})$ & 0.058 \\
\hline Forchheimer coefficient, $c_{E}$ & 0.244 & Fluid effective thermal conductivity, $k_{\text {eff } f}(\mathrm{~W} / \mathrm{m} \mathrm{K})$ & 0.0237 \\
\hline Dry solid density, $\left\langle\rho_{s}\right\rangle^{s}\left(\mathrm{~kg} / \mathrm{m}^{3}\right)$ & 1250 & Fluid effective diffusivity, $D_{\text {eff } f}\left(\mathrm{~m}^{2} / \mathrm{s}\right)$ & $1.522 \times 10^{-6}$ \\
\hline
\end{tabular}

plane, a zero-gradient boundary condition is specified for all quantities except for pressure, which is set to an atmospheric value; on the symmetry $(y=0)$ plane, normal gradients are set to zero for all quantities with the exception of the normal $(v)$ velocity component, which is set to zero; on the wall $(y=D / 2)$, no-slip/ impermeable conditions are set for velocity combined with a zero flux (i.e. insulated) condition for heat and mass transfer, while pressure was extrapolated.

The coal particles water activity is defined as [33],

$a_{W}=1-\exp \left(-14.027\left\langle T_{s}\right\rangle^{s^{0.62}}\left\langle Y_{W_{S}}\right\rangle^{s^{2.7}}\right)$

We also introduce an expression to characterize the effective liquid-in-solid diffusivity as,

$D_{e f f, s}=\left(2.0 \times 10^{-10}\right) \times \frac{\left(\left\langle Y_{W_{S}}\right\rangle^{s}\right)^{n}}{S h}\left(\left\langle T_{s}\right\rangle^{s}-273.15\right)^{3.3}$

where $n$ is a calibration exponent, having a range between 3.5 and 6.5 for different particle liquid moisture fractions. It is worth mentioning that $D_{\text {eff.s }}$ is the only element of calibration required in the present formulation, and this is simply required to give the correct dependence of $D_{\text {eff.s }}$ with moisture and temperature, a relationship that can be provided experimentally. To this end, the temperature dependence in Eq. (43) is directly adopted from Stakić and Tsotsas [33]. The liquid moisture dependence requires calibration however, since the model they used for the drying kinetics had some dependence on the shrinking particle diameter $[33,43]$ while our model neglects shrinkage. The average values of the solid diffusion coefficient fall between $2.0 \times 10^{-8}$ and $2.4 \times 10^{-10}$, which match relatively well with reported literature on the overall drying effective diffusivity [44]. Local Nusselt and Sherwood numbers are based on correlations reported by Ginzburg and Savina [45], which are preferred in cases of relatively large particles [33]. The correlations take the forms,

$N u=\frac{h_{f_{s}} d_{P}}{k_{f}}=C_{T} \cdot \operatorname{Re}_{d_{P}}^{m_{T}} \cdot \operatorname{Pr}_{d_{P}}^{n_{T}}$

$S h=\frac{h_{f s m} d_{P}}{D_{f}}=C_{m} \cdot R e_{d_{P}}^{m_{m}} \cdot S c_{d_{P}}^{n_{m}}$

where $n_{T}=n_{m}=0.33$ and for $R e_{d_{p}}>300, C_{T}=C_{m}=0.977$ and $m_{T}=m_{m}=0.595$ while for, $R e_{d_{p}} \leqslant 300, \quad C_{T}=C_{m}=1.83$ and $m_{T}=m_{m}=0.485$.

Figs. 6 and 7, show the average solid constituent's moisture content and temporal temperature variation for the coal packed bed on the symmetry line of the bed. The comparison between the present model and the experiment reported by Stakić and Tsotsas [33] shows excellent agreement in terms of the physical trends suggesting that the dynamic coupling model correctly represents the physics of the drying problem. The rate of drying is observed to change as a function of different factors that interplay together to cause the observed drying regimes. These factors include the temperature variation, water activity, effective diffusivity variation and mode of interstitial mass transfer (i.e. whether the convective expression is active or the diffusive one). One may conclude however that the rate of drying becomes very low at an average

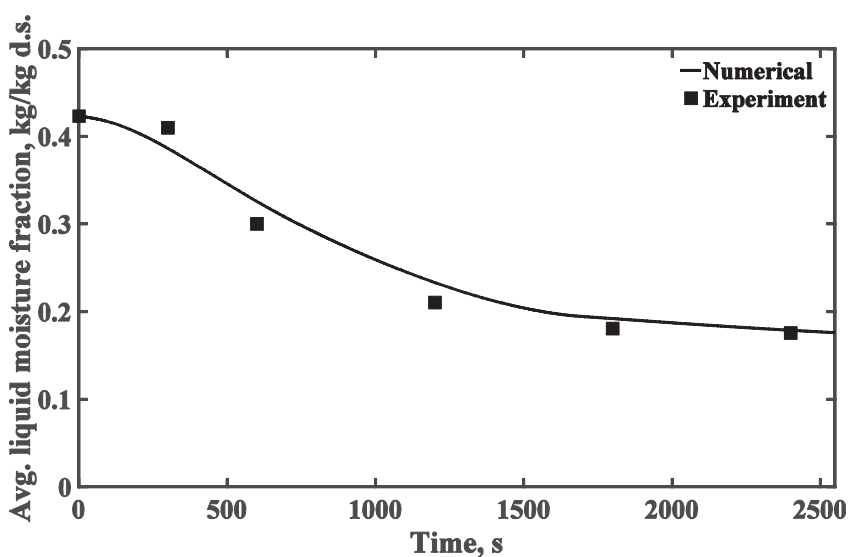

Fig. 6. Temporal variation of the coal bed averaged liquid mass fraction compared to the experimental results reported in Stakić and Tsotsas [33].

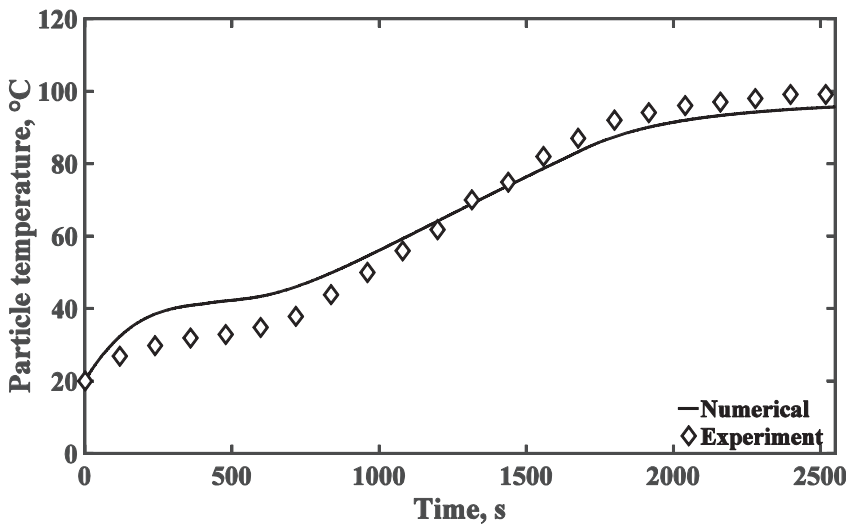

Fig. 7. Temporal variation of the coal bed averaged solid particle temperature compared to the experimental results reported in Stakić and Tsotsas [33].

moisture content of about $0.17 \mathrm{~kg} / \mathrm{kg}$ dry solid which may be called 'the equilibrium moisture content' of the present case of drying. The temperature variation shown in Fig. 7 indicates that heating of the cold bed solid particles is non-linear in time, depending on whether the drying rate is high enough so that the energy supplied with incoming air is utilized directly in evaporation (i.e. supplies an amount of heat that is almost equal to the amount that the solid constituent contributes with in the evaporation) or is utilized sensibly to heat the bed (i.e. the drying rate is small so that heat is mostly raising the enthalpy of the solid constituent). Arriving at the correct trend for heat transfer in Fig. 7 was possible using the $\dot{H}_{f s}^{\text {mass }}$ term as defined in Eq. (28).

Fig. 8 illustrates the variation of the liquid moisture fraction, fluid temperature and particle temperature along the height of the bed at different instants in time. A typical drying scenario is observed for the liquid moisture, wherein a drying front propagates from inlet to outlet with increasing time. The drying front 

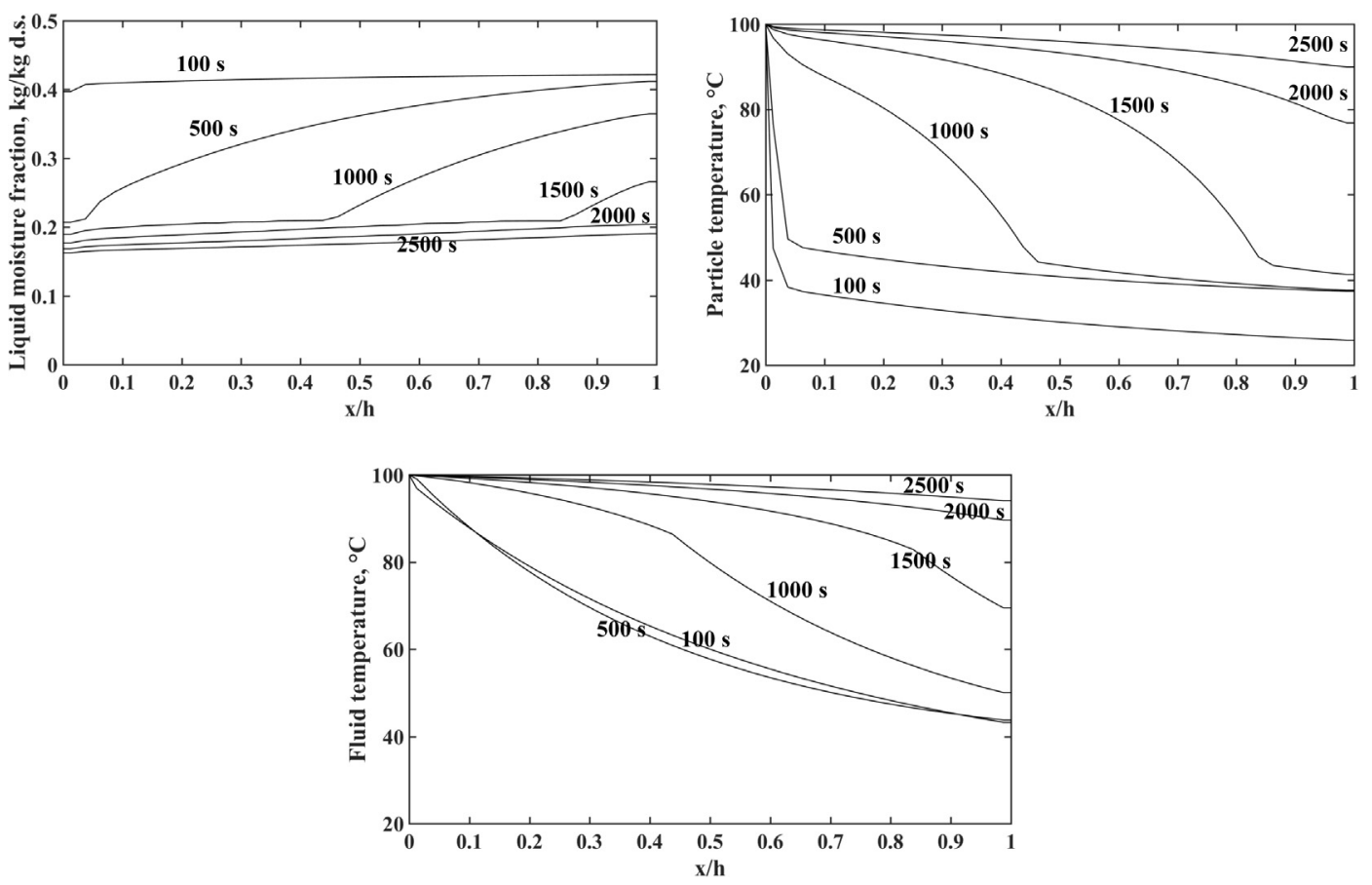

Fig. 8. Axial variation of the centerline value for liquid moisture fraction, particle and void temperatures at different simulation times.

moves as the air capacity becomes exhausted. The drying capacity is different in the coal-drying case as compared to other more highly saturated materials (i.e. particles with saturated surfaces), since lower water activities tend to decrease this capacity, resulting in a final moisture content that is still relatively high. To elaborate further on this point, the rate of local mass transfer is much lower in the present case as the local difference between the coal temperature-dependent water activity and air relative humidity decreases. This is consistent with information present in the literature about coal drying. If we compare this to the case of drying of wet wood wool that was reported by Khan et al. [25], the absence of water activity and its temperature-dependence in their interface model results in predictions of dry-out of the wood wool. A gradual increase of fluid and particle temperature is also illustrated in Fig. 8, in which a heating front propagates in an analogous manner to the drying front. The rate at which fluid is being heated is significantly faster than the rate of particle heating which indicates the strong thermal non-equilibrium and the fact that the thermal resistance inside the solid is low as compared to the fluid-side resistance. This also indicates that most of the mass transfer energy is withdrawn from the solid constituent.

\subsection{Drying of an apple slice}

The present section builds on the coal particle drying simulation, which focused on dynamic coupling at microscopic interfaces inside a porous region, and presents a conjugate case that contains both microscopic and macroscopic interfaces, where the macroscopic interface is subject to diffusively dominant mass transfer. The problem considered is the convective drying of an apple slice. The domain that we adopt here is the same as that utilized by Khan and Straatman [9] to mimic experiments conducted by Velić et al. [35]. In their study, a $20 \times 20 \times 5 \mathrm{~mm}^{3}$ rectangular (peeled) apple slice was placed in an air stream with an inlet condition of $60{ }^{\circ} \mathrm{C}$ and $9 \%$ relative humidity, with inlet air velocities in the range $0.64-2.75 \mathrm{~m} / \mathrm{s}$. Herein, our base case is selected to have an inlet air velocity of $1.5 \mathrm{~m} / \mathrm{s}$. The domain of study utilizes symmetry to reduce the domain of the problem to a quarter of the apple slice with part of the surrounding air stream simulated [9]. The simulation setup is directly adopted from Khan and Straatman [9], including the mesh $(30 \times 20 \times 20$ control-volumes with refinement in proximity of all fluid/porous interfaces) and the time-step specification (50 s with gradual increase from the beginning of the simulation for purposes of numerical stability). A typical simulation of this case required approximately 29 min of wall-clock time. Fig. 9 shows the simulation setup. Boundary conditions were imposed as follows: at the inlet $(x=0)$ plane, velocity was specified as $(u$, $v, w)=(1.5,0,0) \mathrm{m} / \mathrm{s}$ with a temperature of $60^{\circ} \mathrm{C}$ and $9 \%$ relative humidity, with pressure extrapolated from inside the domain; at the outlet $(x=L)$ plane, zero-gradients were specified for all quantities except for pressure, which was set to atmospheric; on the symmetry planes ( $y=0$ and $z=0$ ), zero-gradients for all quantities except for the normal velocity component, which was set to zero; on the top and right-side faces of the domain, a zero-gradient is specified for all quantities except for pressure, which is extrapolated from inside the domain. The apple slice is specified to have an initial moisture content of $7.45 \mathrm{~kg} / \mathrm{kg}$ dry solid [9]. Table $2 \mathrm{sum}$ marizes the values of the properties required for the present simulations, as cited from [9]. To evaluate the two apple diffusivities,

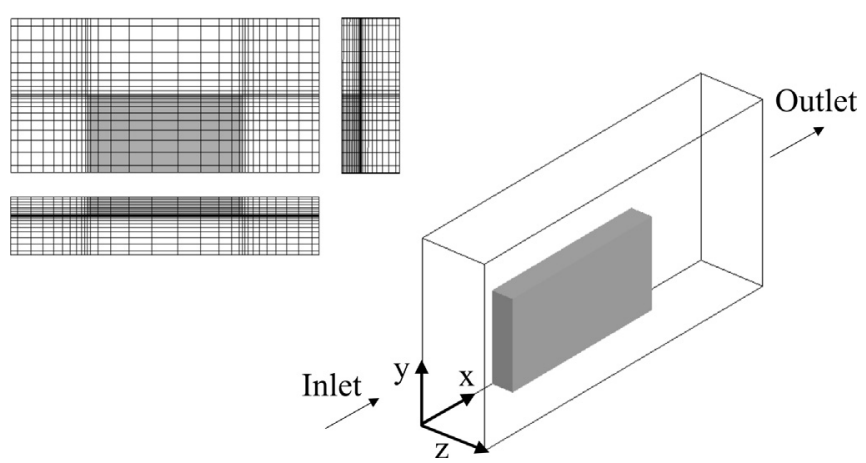

Fig. 9. Schematic and grid used for simulation of drying of an apple slice. 
Table 2

Apple slice drying properties [9].

\begin{tabular}{|c|c|c|c|}
\hline Porosity, $\varepsilon$ & 0.206 & Specific interfacial area, $A_{f s}\left(\mathrm{~m}^{-1}\right)$ & 11650 \\
\hline Permeability, $K\left(\mathrm{~m}^{2}\right)$ & $8.89 \times 10^{-13}$ & Average particle diameter, $d_{p}(r \mu \mathrm{m})$ & 103 \\
\hline Forchheimer coefficient, $c_{E}$ & 0.244 & Solid effective thermal conductivity, $k_{\text {eff,s }}(\mathrm{W} / \mathrm{m} \mathrm{K})$ & 0.3335 \\
\hline Dry solid density, $\left\langle\rho_{s}\right\rangle^{s}\left(\mathrm{~kg} / \mathrm{m}^{3}\right)^{\mathrm{a}}$ & 124.85 & Fluid effective thermal conductivity, $k_{\text {eff. } f}(\mathrm{~W} / \mathrm{m} \mathrm{K})$ & 0.0865 \\
\hline Dry solid specific heat, $c_{p s}(\mathrm{~J} / \mathrm{kg} \mathrm{K})$ & 252 & & \\
\hline
\end{tabular}

a The dry solid density is the solid matrix density multiplied by the solid volume fraction, provided by Khan and Straatman [9].

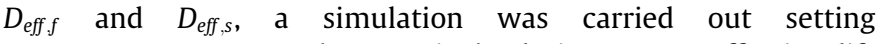
$D_{f}=D_{\text {eff. } f}=D_{\text {eff }, s}=D_{\text {eff }}$, where $D_{\text {eff }}$ is the drying process effective diffusivity obtained directly from Velić et al. [35], and the resulting trend have been matched to their experiment.

This approach is identical to the one used by Khan and Straatman [9], given the absence of reliable diffusivity information from the literature. Herein, $D_{\text {eff. } f}$ is evaluated by carrying out the fluid leg mass flux balance given by Eq. (30) using this simulation result and setting $D_{f}$ to its true value. The same procedure was used to obtain an initial estimate for $D_{\text {eff.s }}$, which was calibrated later to obtain a better match with the experiment at different inlet velocities. Fig. 10 shows the variation of the diffusivities with liquid moisture ratio (ratio of moisture content to initial moisture content). The trend for the variation of the fluid diffusivity is similar to the variations reported for vapor diffusion in the literature [46]. The trend of the liquid-in-solid effective diffusivity varies within the same orders of magnitude as given by Khan and Straatman [9] and is reasonable in terms of the order of magnitude comparison to the overall drying effective diffusivity obtained from Velić et al [35]. Local heat and mass transfer correlations are different from calibrated correlations utilized in the work of Khan and Straatman [9], which are taken from Geankoplis [47] for spherical particles. The correlations involve a fixed term that is independent of the flow and a variable term, given as,

$N u=\frac{h_{f_{s}} d_{P}}{k_{f}}=C_{T 1}+C_{T} \cdot \operatorname{Re}_{d_{P}}^{m_{T}} \cdot \operatorname{Pr}_{d_{P}}^{n_{T}}$

$S h=\frac{h_{f s m} d_{P}}{D_{f}}=C_{m 1}+C_{m} \cdot R e_{d_{P}}^{m_{m}} \cdot S c_{d_{P}}^{n_{m}}$

where $C_{T 1}=C_{m 1}=2, \quad C_{T}=C_{m}=0.552, \quad m_{T}=m_{m}=0.53 \quad$ and $n_{T}=n_{m}=0.33$ for $1<R e_{d_{p}}<48,000$.

In regards to the local water activity, Toujani et al. [48] obtained the water activity of apple slices at temperatures up to $70{ }^{\circ} \mathrm{C}$. Water activities below 70\% occur for moisture contents below $0.3 \mathrm{~kg} / \mathrm{kg}$ dry. Given that the present apple slice starts at $7.45 \mathrm{~kg} /$

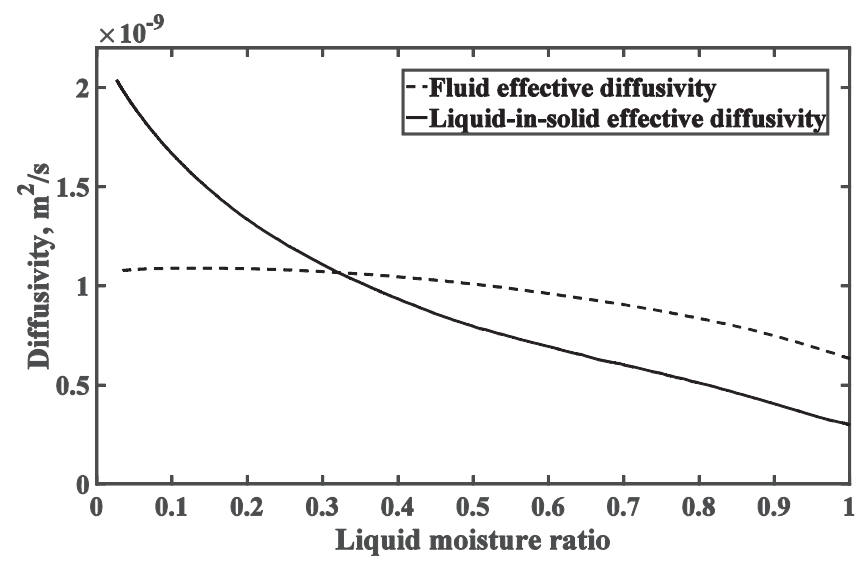

Fig. 10. Apple diffusivities as a function of the liquid moisture ratio. kg dry solid, it was deemed suitable to assume particle surface saturation for the convective interstitial mode of mass transfer.

The present case starts with a diffusively-dominant mode for mass transfer, since the liquid-in-solid diffusivity is small enough that the macroscopic diffusive resistance at the fluid/porous interface is the rate determining resistance. This is consistent with the reports in the literature about absence of a constant drying rate period for some fruits and vegetables drying experiments $[35,49,50]$. The ratio $\left\langle Y_{W, s}\right\rangle_{e}^{s} /\left\langle Y_{v f f}\right\rangle_{e}^{f}$ in Eq. (38) for the present case is determined based on the instantaneous average moisture content of the whole apple slice for all the macroscopic interfaces as a means for simplification and better convergence characteristics. Fig. 11 shows the variation of the average moisture ratio with time for inlet velocities of $0.64,1.5$ and $2.75 \mathrm{~m} / \mathrm{s}$, and shows that the physical effect of changing flow velocities is achieved with the current coupling technique; i.e., the higher the velocity, the faster the drying rate. The agreement between the model and experiment is generally good and is best for the middle flow velocity in terms of the trend and margin. While the low and high speeds show qualitative agreement, larger discrepancies between model and experiment are evident. One reason for the larger discrepancies could be the velocity effect on enhancing vapor diffusion through the interface dry solid layer. It is observed that the present model accounts for advective effects on the drying boundary layer for convectivelydominant modes of mass transfer. However, for the diffusivelydominant mode, the expression used for the vapor transport inside the dry solid layer given by Eq. (37) is purely diffusive. It is physically reasonable however that the higher the velocity passing across the macroscopic interface, the higher the rate of vapor transport that can happen through the dry layer into the air stream [51]. This effect can be accounted for by modifying the expression used for the phase ratio as,

$\mathrm{K}=\frac{1}{\beta}\left(1-\frac{1}{1+\frac{\left\langle\rho_{s}\right\rangle_{E}^{S} D_{e f f, s}\left\langle Y_{w, s}\right\rangle_{e}^{s}}{\rho_{f_{P}}(1-\varepsilon) D_{f}\left\langle Y_{v f}\right\rangle_{e}^{f}}}\right)$

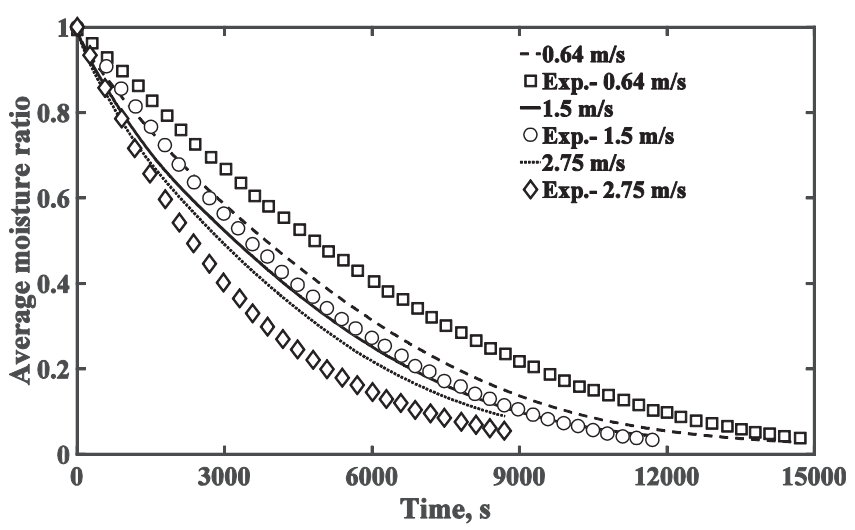

Fig. 11. Temporal variation of the averaged apple moisture ratio for different inlet velocities compared to the experimental results of Velić et al. [35]. 
where $\beta$ is a coefficient that we introduce as a vapor diffusion enhancement factor [52]. Fig. 12 reproduces the drying rate plots given in Fig. 11, with the inclusion of Eq. (48) using $\beta$ values of $0.87,1$ and 1.11 for $0.64,1.5$ and $2.75 \mathrm{~m} / \mathrm{s}$, respectively. While this approach introduces a calibration factor, it is shown to reduce the discrepancies to within a maximum of $4 \%$ of the experiments.

It is of particular interest to show how the present model approaches the physical threshold of moisture capacity. In Khan and Straatman [9], the moisture threshold was achieved, but an adhoc exponentially-varying coefficient was required to properly approach the threshold. Considering first the influence of inlet relative humidity, Fig. 13 shows the temporal variation of the average moisture ratio for $1.5 \mathrm{~m} / \mathrm{s}$ with inlet relative humidities of 9, 40, 70 and $90 \%$. The drying rate is shown to decline smoothly as the relative humidity increases until it becomes very weak at the $90 \%$ case, adhering to the expected physical behavior as the capacity of the air to entrain vapor moisture decreases. Considering the influence of increasing inlet temperature, Fig. 14 shows the different drying rates achieved at a fixed inlet specific humidity. A decrease of the drying rate is observed with increasing incoming air stream temperature, which is also consistent with the physics of the problem. In this manner, the present formulation inherently incorporates the changing physics associated with approaching moisture thresholds without the need for additional tuning or calibration.

Spatial and temporal variation of the solved moisture and temperature fields are shown in Figs. 15-17. Temporal variation of the liquid moisture distribution is shown in Fig. 15, where it is observed that the liquid moisture decreases inside the apple slice

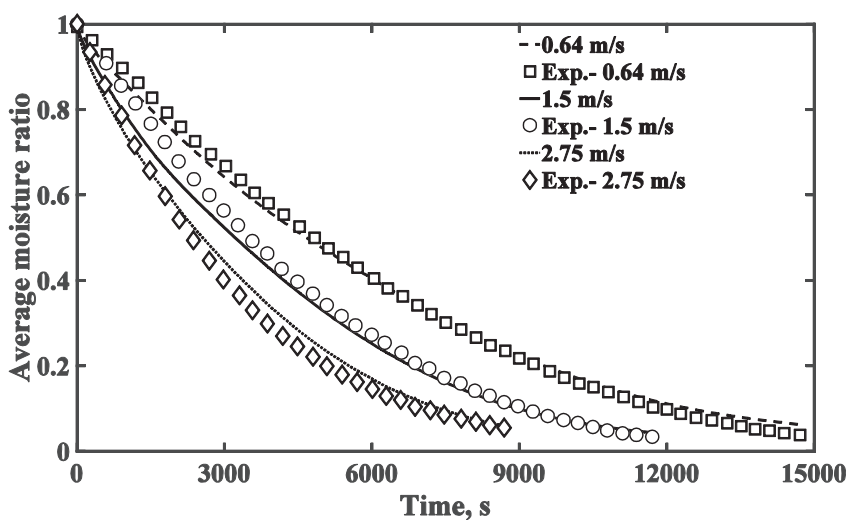

Fig. 12. Temporal variation of the averaged apple moisture ratio for different inlet velocities accounting for the advective effects; comparison to the experimental results of Velić et al. [35].

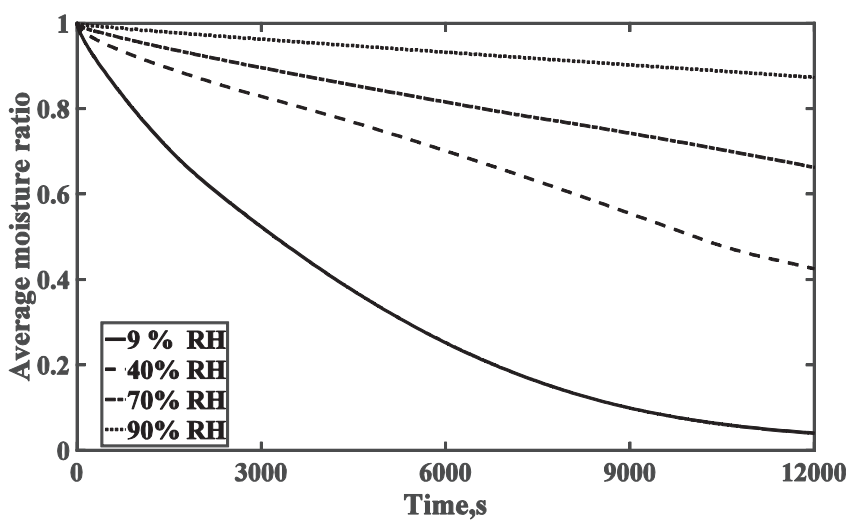

Fig. 13. Temporal variation of the averaged apple moisture ratio as a function of inlet airflow relative humidity for $1.5 \mathrm{~m} / \mathrm{s}$ inlet velocity.

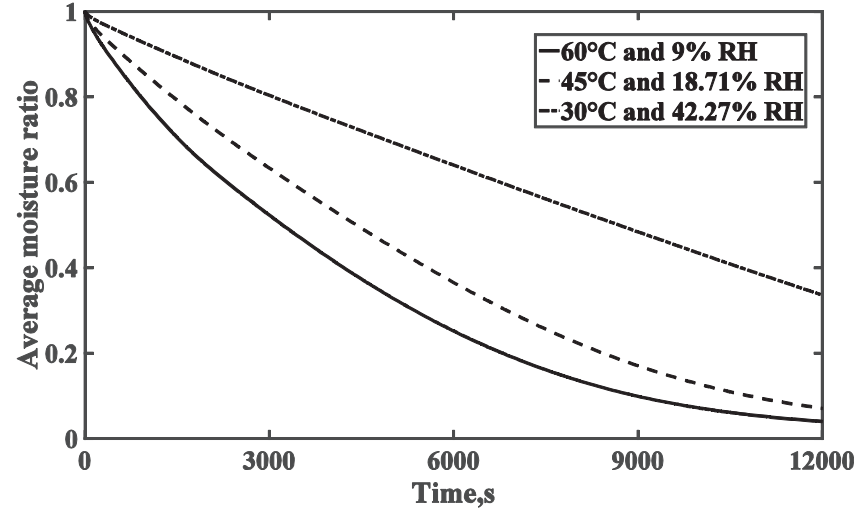

Fig. 14. Temporal variation of the averaged apple moisture content as a function of the inlet temperature at a fixed inlet specific humidity for $1.5 \mathrm{~m} / \mathrm{s}$ inlet velocity.

gradually as the material dries up with faster rate closer to the leading edge of the apple slice. The relative humidity is highest inside the apple flesh. In this case the void space becomes quickly saturated with vapor indicating that most of the mass transfer occurs at the fluid/porous interfaces, which is attributed to the low porosity of the apple slice. The relative humidity of the surroundings is highest when the drying rate is high and it declines as the rate that air picks up moisture from the apple slice decreases. The contours of fluid and solid temperature inside the apple slice, shown in Figs. 16 and 17, show similar variation with a small degree of thermal non-equilibrium. The core of the apple is cool when the mass transfer rate (drying rate) is high, as seen at 500 seconds, because the inner part of the apple slice supplies most of the vaporization energy. As the apple slice dries, the rate of mass transfer decreases and the core starts to warm up, taking sensible heat from the surrounding. The behavior is physically reasonable and it is consistent with the fear of frost injuries that is of concern to the drying industry of fruits and vegetables.

\subsection{Dehydration of mineral plaster}

Convectively-dominant mass transfer is verified herein by simulating a case of dehydration of mineral plaster, as adopted from the work of Defraeye et al. [8]. This case was selected because it provides the necessary information and relevant properties, especially the diffusivities, which are not easily found in the literature, and because the constant drying-rate period is long and clearly visible [8]. This particular case has not been experimentally tested but different modeling approaches have been utilized to simulate and analyze it [8]. While the total simulation time of the case is 15 days, which is the time it takes to fully dehydrate the mineral plaster under consideration, we are mainly interested in the first two hours of the simulation since this is a period of convectivelydominant drying and is well within the constant drying rate period as reported by Defraeye et al [8]. The simulation setup is based on a small-scale wind tunnel test section reported in the work of James et al. [53] shown in Fig. 18. A long inlet section (not included in the simulation) provides fully-developed laminar flow to the surface of a plaster substrate, which is comprised of mineral plaster placed inside a heat and mass insulated enclosure. The test section is $500 \mathrm{~mm}$ long with heights of the porous and air regions of $37.5 \mathrm{~mm}$ and $20.5 \mathrm{~mm}$, respectively.

Boundary conditions were imposed as follows: at the inlet, air enters the channel at $23.8{ }^{\circ} \mathrm{C}$ and $71.9 \%$ relative humidity with a mass flow rate based on a bulk air velocity of $0.8 \mathrm{~m} / \mathrm{s}$ with pressure extrapolated from inside the domain; all walls were assigned no-slip, no-penetration boundary conditions with pressure 


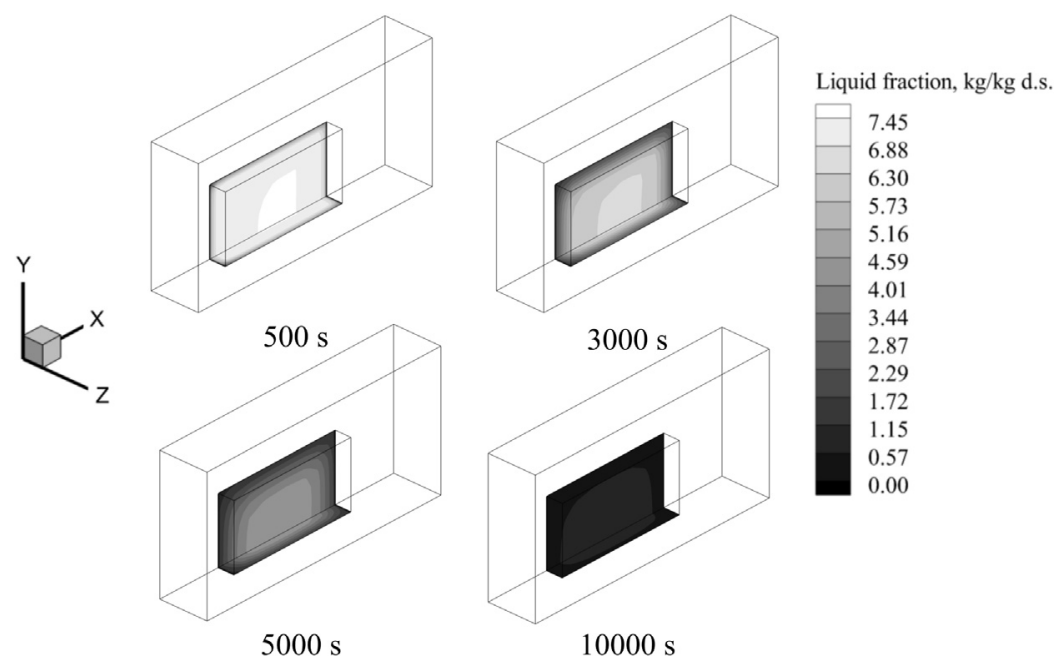

Fig. 15. Contour plots for liquid apple moisture spatial variation along the domain-cutting symmetry planes at different time instances.

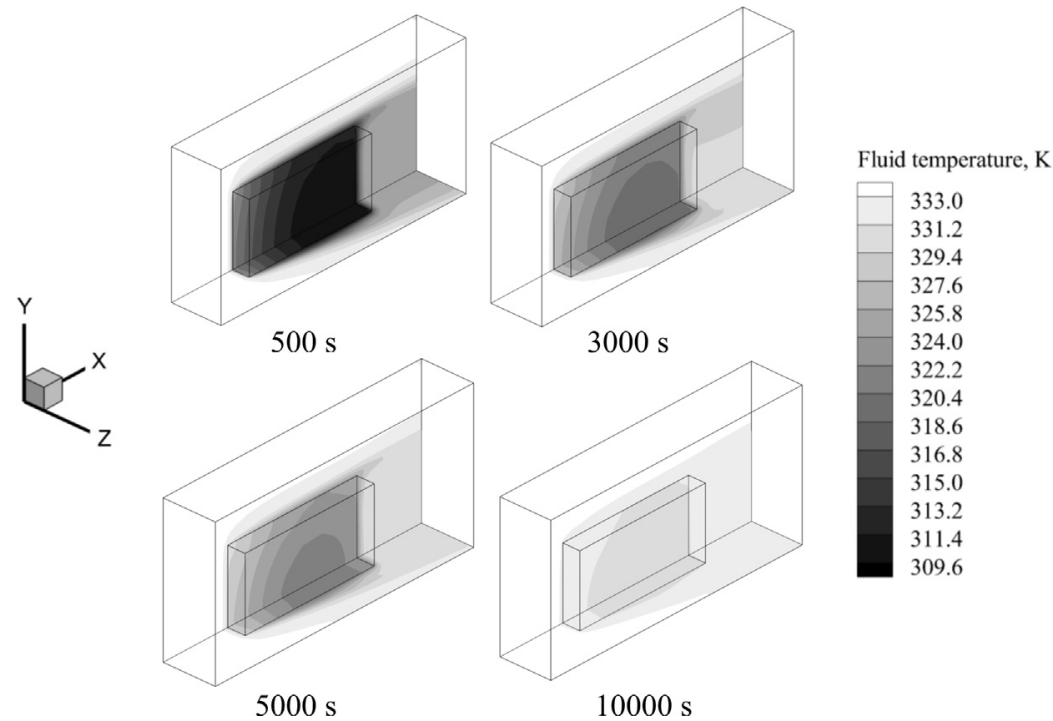

Fig. 16. Contour plots for fluid temperature spatial variation along the domain-cutting symmetry planes at different time instances.

extrapolated from inside the domain. In addition, the walls did not admit heat or mass transfer. At the channel outlet, a zero-gradient condition was used for all variables, with the exception of pressure, which was set to atmospheric. The plaster was given an initial temperature of $20^{\circ} \mathrm{C}$. A mesh of $172 \times 74 \times 1$ control volumes was used based on the same spatial resolution as the work of Defraeye et al. [8]. The simulation was carried out based on an adaptive time stepping approach that was necessary to achieve convergence given the high time and space non-linearity of the problem. A typical simulation requires several hours in this problem given the above reasons, which is expected based on information from Defraeye et al. [8].

Mineral plaster is a form of plaster that have a low chemical content of water, given by the formula $\left(\mathrm{CaSO}_{4} \cdot \frac{1}{2} \mathrm{H}_{2} \mathrm{O}\right)$. Table 3 summarizes the relevant mineral plaster properties. Since Defraeye et al [8], treated the material as non-porous, they did not specify the values of the pore diameter and the porosity, which were selected herein from Bochen [54]. The permeability was calculated using the Ergun equation [42] and the specific surface area using the porosity and the particle diameter. The solid specific heat was based on Defraeye et al [8] while the fluid and solid conductivity were apportioned based on the porosity and their overall porous material conductivity.

The dry solid density and the initial moisture content was calculated based on an initial water content and a total solid mass of $126 \mathrm{~kg} / \mathrm{m}^{3}$ and $1615 \mathrm{~kg} / \mathrm{m}^{3}$ of the whole porous material, respectively [8]. The initial liquid moisture mass fraction is $0.078021 \mathrm{~kg} /$ $\mathrm{kg}$ dry solid. Fig. 19 shows the trends of variation for the fluid and solid diffusivities. The fluid diffusivity was calculated based on the provided expression of vapor permeability by Defraeye et al. [8]. The primary liquid transport mechanism considered in their work is the capillary forces as they solved for capillary pressure as a transport variable. In our formulation we consider the capillary effect through a gradient-type diffusion expression and hence, it was necessary to link both approaches by equating the two expressions for the liquid transport flux. Utilizing their correlation for relating the capillary pressure and the liquid mass fraction, we were able to arrive at a suitable correlation after smoothing and curve fitting. The liquid diffusivity endures a sharp drop that is consistent with the fact that mineral plaster is a non-hygroscopic material. This sharp drop and the relatively high initial value of the diffusion coefficient are the main reason why the convective 


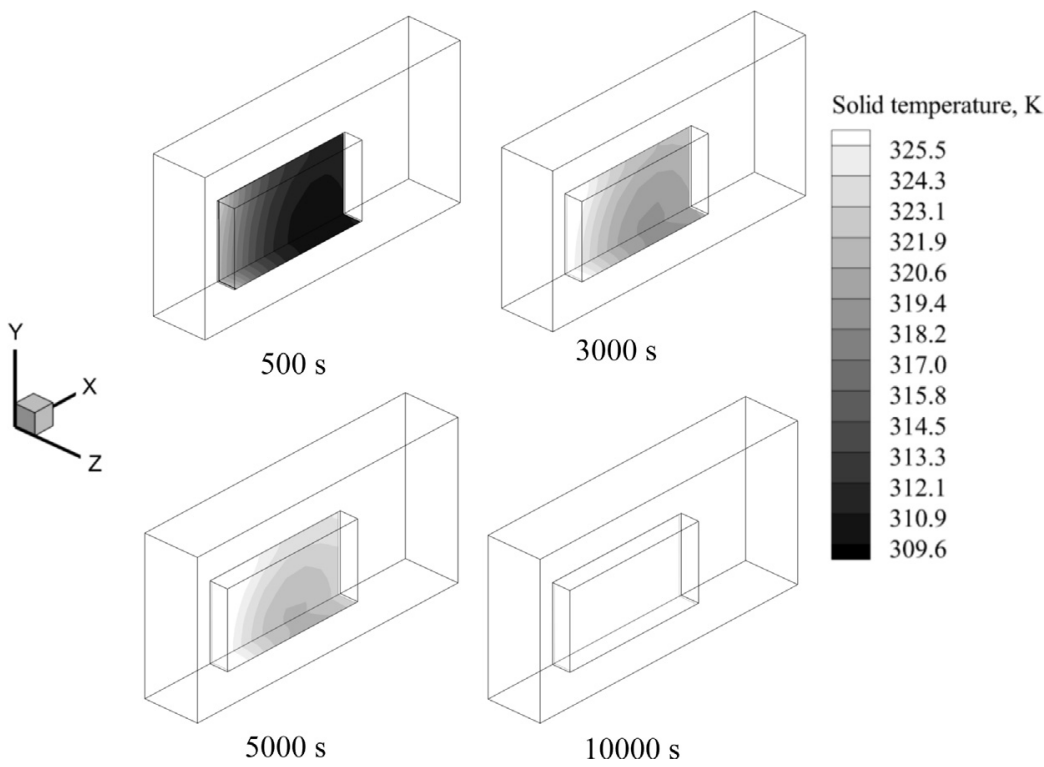

Fig. 17. Contour plots for solid temperature spatial variation along the domain-cutting symmetry planes at different time instances.

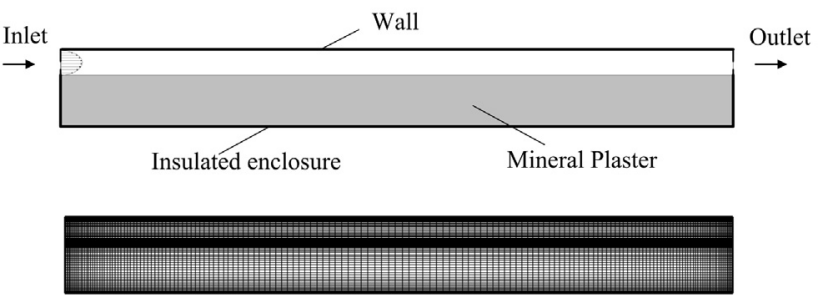

Fig. 18. Simulation setup for the mineral plaster dehydration process.

domination is observed clearly in this simulation. With respect to the water activity, the surface of the solid constituent is assumed saturated as the case should be for a non-hygroscopic material [6]. Eqs. (46) and (47) are used for the local heat and mass transfer correlations and the mass transfer correlation is also utilised at the macroscopic interface.

Fig. 20 displays the average moisture ratio change with time. The material only loses $1.75 \%$ of its moisture content in this time, since the total drying time is on the order of 15 days. The profile shows a consistent decrease of moisture with time without any abrupt changes in the drying rate, which is compatible with the notion of a constant drying rate period. The contour plots for the liquid moisture content displayed in Fig. 21 are very similar to those displayed in Defraeye et al. [8]. The plots show a gradual moisture decrease, which starts at the leading edge of the plaster and moves into the core slowly until it reaches the downstream bottom corner. The contours for relative humidity and temperature are shown in Figs. 22 and 23. Typical boundary layer growth is observed for both relative humidity and fluid temperature, as relative humidity increases along the channel and temperature

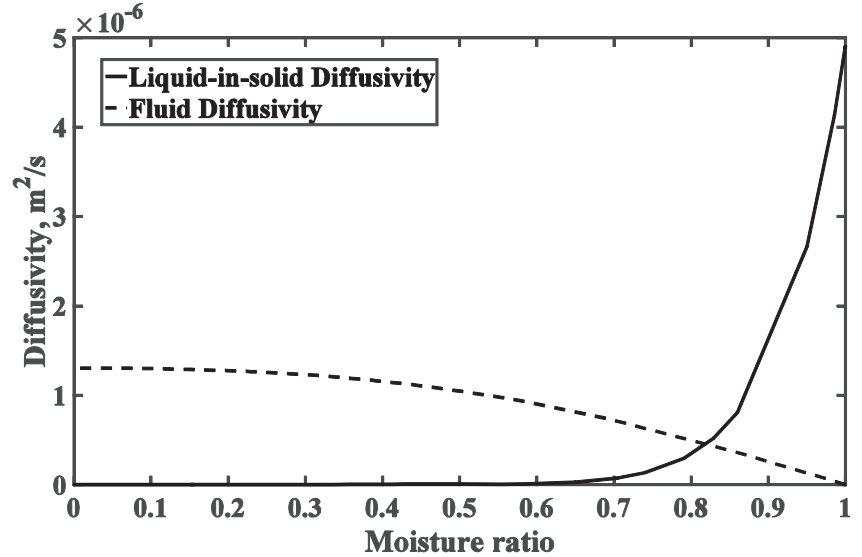

Fig. 19. Mineral plaster diffusivities as a function of the moisture ratio.

decreases indicating that the air stream is the main source of vaporization energy. Within the porous region itself, the temperature is nearly constant at a value that is very close to the wet bulb temperature (approximately $20^{\circ} \mathrm{C}$ [8]), indicating that vaporization heat removed from the porous region is restored sensibly by energy provided from the air. Very small temperature deviations (less than $0.3^{\circ} \mathrm{C}$ ) are computed inside the porous material, but not resolved in the figures. These temperatures are higher for locations that have lower moisture contents forming fronts that are analogous to the ones shown in Fig. 21.

As a final means of comparison, the average surface heat and mass transfer coefficients over the length of the macroscopic interface are evaluated based on the definitions used by Defraeye et al.

Table 3

Mineral plaster properties.

\begin{tabular}{|c|c|c|c|}
\hline Porosity, $\varepsilon$ & 0.15 & Specific interfacial area, $A_{f s}\left(\mathrm{~m}^{-1}\right)$ & 112500 \\
\hline Permeability, $K\left(\mathrm{~m}^{2}\right)$ & $2 \times 10^{-15}$ & Average Particle diameter, $d_{p}(\mu \mathrm{m})$ & 8 \\
\hline Forchheimer coefficient, $c_{E}$ & 0.244 & Solid effective thermal conductivity, $k_{\text {eff }, s}(\mathrm{~W} / \mathrm{m} \mathrm{K})$ & 1.02 \\
\hline Dry solid density, $\left\langle\rho_{s}\right\rangle^{s}\left(\mathrm{~kg} / \mathrm{m}^{3}\right)$ & 1900 & Fluid effective thermal conductivity, $k_{\text {eff. } f}(\mathrm{~W} / \mathrm{m} \mathrm{K})$ & 0.18 \\
\hline Dry solid specific heat, $c_{p s}(\mathrm{~J} / \mathrm{kg} \mathrm{K})$ & 1050 & & \\
\hline
\end{tabular}




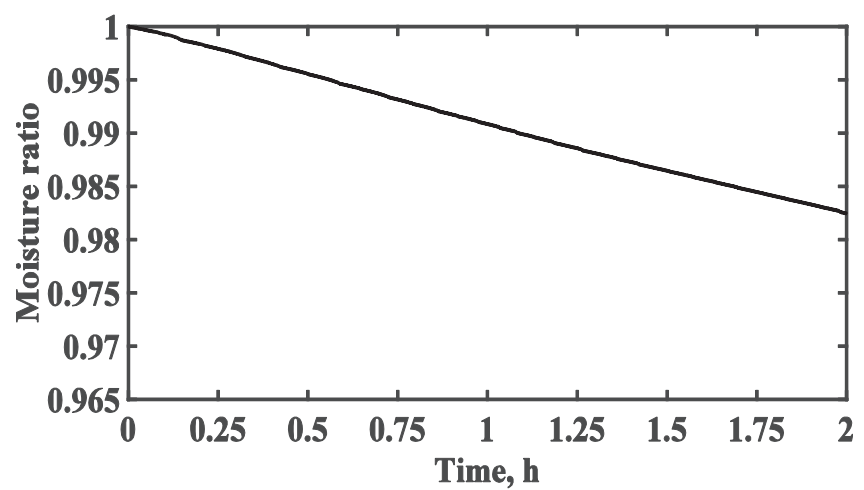

Fig. 20. Variation of the average moisture ratio as a function of the drying time for mineral plaster.
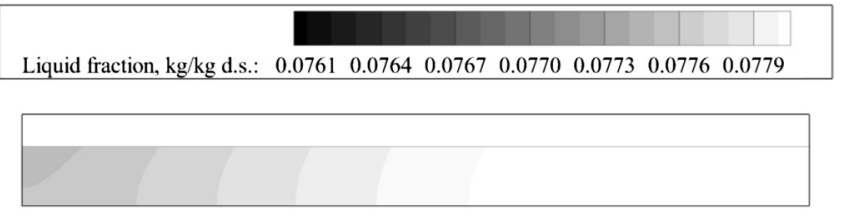

a) 1 hour

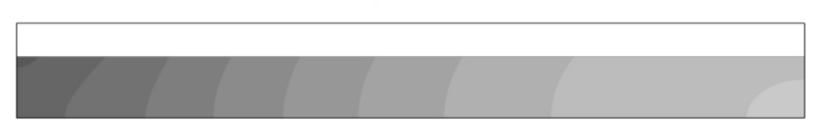

b) 2 hours

Fig. 21. Temporal variation for the distribution of liquid moisture content of mineral plaster (a scale with four decimal places was necessary to observe the moisture fronts).

Relative humidity: 0.720 .760 .800 .840 .880 .920 .961 .00

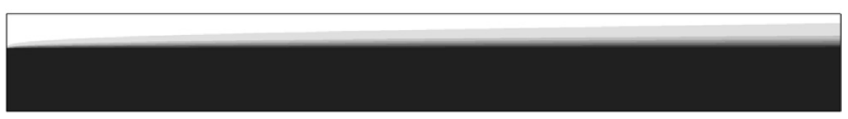

Fig. 22. Relative humidity distribution at $1 \mathrm{~h}$ of simulation time for mineral plaster.

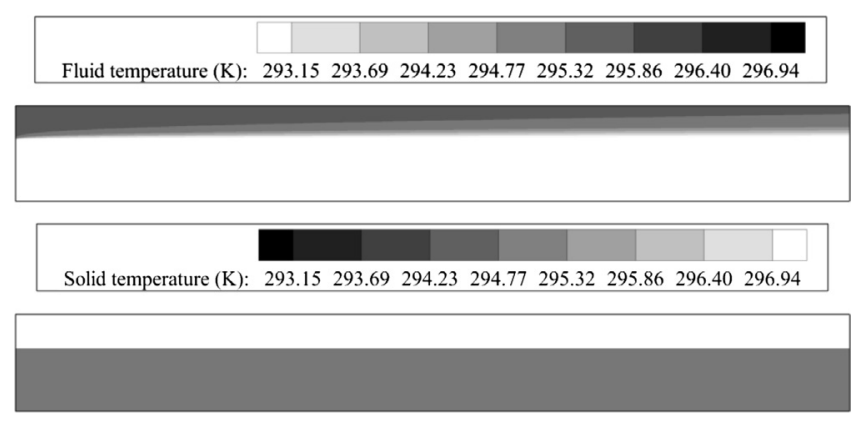

Fig. 23. Distributions of temperatures at $1 \mathrm{~h}$ of simulation time for mineral plaster.

[8]. The present simulation yields a mass transfer coefficient of $5.73 \times 10^{-8} \mathrm{~s} / \mathrm{m}$ (based on vapor pressure) as compared to $3.77 \times 10^{-8} \mathrm{~s} / \mathrm{m}$, while for heat transfer, an average coefficient of $2 \mathrm{~W} / \mathrm{m}^{2} \mathrm{~K}$ was computed compared to $5.34 \mathrm{~W} / \mathrm{m}^{2} \mathrm{~K}$. Given the different modelling approaches, and in particular, our porous verses their non-porous formulation, the computed values compare very well for both heat and mass transfer.

\section{Summary}

In the present study, a dynamically-coupled approach has been introduced for modelling heat and mass transfer in conjugate fluid/porous domains. The dynamic-coupling means that heat and mass exchanges between constituents inside the porous media (microscopic level) and across fluid/porous interfaces (macroscopic level), vary dynamically in response to the local spatial and temporal condition of the interface. The key novelties are summarized as:

- Models are presented that track the variations of heat and mass transfer resistances inside the fluid and solid phases and allow for switching between expressions developed for these heat and mass exchanges on both scales without the sacrifice of numerical stability.

- A technique for apportioning of the vaporization energy on different phases is incorporated.

- A concept is introduced for the phase ratio, which is implemented to achieve implicit conjugate coupling at the macroscopic interfaces.

The model involves details that allow the application to very different interface heat and mass transfer problems. Three cases were introduced to validate and illustrate the capability of the model. A coal packed bed of particles is simulated to verify the interstitial coupling approach of the formulation. Results of the moisture and temperature profiles showed excellent agreement in terms of trends and thresholds. The case of drying of an apple slice was tested to verify the efficacy of the dynamic macroscopic coupling for diffusively-dominant mass transfer. Comparison to experiments indicated an agreement to within $4 \%$ in terms of drying rates and time. In addition, the physical thresholds of relative humidity and temperature were approached smoothly without the need for additional tuning, a feature that makes the present formulation particularly attractive. Finally, a convectivelydominant case of mineral plaster dehydration was simulated. The predicted boundary layer growth, nearly constant material temperature and the gradual propagation of the drying fronts inside the porous materials showed that the physics of the problem are accurately represented, and heat and mass transfer rates compare well to previous work on the same problem. Thus, it is concluded that the present dynamic-coupling approach is capable of representing the physics of heat and mass transfer across interfaces between different phases in a generic way without case specificity and with a lesser level of empiricism than any existing modelling approach. This means that the present model, with little calibration or tuning, is capable of modelling non-equilibrium heat and mass transfer for both diffusively and convectively-dominated interfaces.

\section{Acknowledgement}

The authors would like to acknowledge the financial support from the Natural Sciences and Engineering Research Council of Canada (NSERC).

\section{References}

[1] A.V. Luikov, Heat and Mass Transfer in Capillary Bodies, Pergamon Press, Oxford, England, 1966.

[2] S. Whitaker, A theory of drying, Adv. Heat Transfer 13 (1977) 119-203.

[3] M.A. Stanish, G.S. Schajer, F. Kayihan, A mathematical model of drying for hygroscopic porous media, AIChE J. 32 (8) (1986) 1301-1311.

[4] R. Younsi, D. Kocaefe, S. Poncsak, Y. Kocaefe, Computational modelling of heat and mass transfer during the high-temperature heat treatment of wood, Appl. Therm. Eng. 27 (8) (2007) 1424-1431.

[5] P. Perré, I.W. Turner, A 3-D version of TransPore: a comprehensive heat and mass transfer computational model for simulating the drying of porous media, Int. J. Heat Mass Transfer 42 (24) (1999) 4501-4521. 
[6] R.B. Keey, Drying: Principles and Practice, International Series of Monographs in Chemical Engineering, vol. 13, 1972.

[7] S.B. Nasrallah, P. Perre, Detailed study of a model of heat and mass transfer during convective drying of porous media, Int. J. Heat Mass Transfer 31 (5) (1988) 957-967.

[8] T. Defraeye, B. Blocken, J. Carmeliet, Analysis of convective heat and mass transfer coefficients for convective drying of a porous flat plate by conjugate modelling, Int. J. Heat Mass Transfer 55 (1) (2012) 112-124.

[9] F.A. Khan, A.G. Straatman, A conjugate fluid-porous approach to convective heat and mass transfer with application to produce drying, J. Food Eng. 179 (2016) 55-67.

[10] P.N. Sarsavadia, R.L. Sawhney, D.R. Pangavhane, S.P. Singh, Drying behaviour of brined onion slices, J. Food Eng. 40 (3) (1999) 219-226.

[11] H.O. Menges, C. Ertekin, Mathematical modeling of thin layer drying of Golden apples, J. Food Eng. 77 (1) (2006) 119-125.

[12] M. Karoglou, A. Moropoulou, Z.B. Maroulis, M.K. Krokida, Drying kinetics of some building materials, Drying Technol. 23 (1-2) (2005) 305-315.

[13] M. Zhang, H. Jiang, R.X. Lim, Recent developments in microwave-assisted drying of vegetables, fruits, and aquatic products - drying kinetics and quality considerations, Drying Technol. 28 (11) (2010) 1307-1316.

[14] H. Perazzini, F.B. Freire, J.T. Freire, Drying kinetics prediction of solid waste using semi-empirical and artificial neural network models, Chem. Eng. Technol. 36 (7) (2013) 1193-1201.

[15] M.R. Islam, J.C. Ho, A.S. Mujumdar, Convective drying with time-varying heat input: simulation results, Drying Technol. 21 (7) (2003) 1333-1356.

[16] M.M. Hussain, I. Dincer, Two-dimensional heat and moisture transfer analysis of a cylindrical moist object subjected to drying: a finite-difference approach, Int. J. Heat Mass Transfer 46 (21) (2003) 4033-4039.

[17] R. Younsi, D. Kocaefe, S. Poncsak, Y. Kocaefe, Thermal modelling of the high temperature treatment of wood based on Luikov's approach, Int. J. Energy Res. 30 (9) (2006) 699-711.

[18] M.K. Chourasia, T.K. Goswami, CFD simulation of effects of operating parameters and product on heat transfer and moisture loss in the stack of bagged potatoes, J. Food Eng. 80 (3) (2007) 947-960.

[19] A. Kaya, O. Aydin, I. Dincer, Numerical modeling of heat and mass transfer during forced convection drying of rectangular moist objects, Int. J. Heat Mass Transfer 49 (17) (2006) 3094-3103.

[20] V.C. Mohan, P. Talukdar, Three dimensional numerical modeling of simultaneous heat and moisture transfer in a moist object subjected to convective drying, Int. J. Heat Mass Transfer 53 (21) (2010) 4638-4650.

[21] J.A. Esfahani, H. Majdi, E. Barati, Analytical two-dimensional analysis of the transport phenomena occurring during convective drying: apple slices, J. Food Eng. 123 (2014) 87-93.

[22] A. Erriguible, P. Bernada, F. Couture, M. Roques, Simulation of convective drying of a porous medium with boundary conditions provided by CFD, Chem. Eng. Res. Des. 84 (2) (2006) 113-123.

[23] C. Lamnatou, E. Papanicolaou, V. Belessiotis, N. Kyriakis, Finite-volume modelling of heat and mass transfer during convective drying of porous bodies - non-conjugate and conjugate formulations involving the aerodynamic effects, Renewable Energy 35 (7) (2010) 1391-1402.

[24] M.V. De Bonis, G. Ruocco, A generalized conjugate model for forced convection drying based on an evaporative kinetics, J. Food Eng. 89 (2) (2008) 232-240.

[25] F.A. Khan, C. Fischer, A.G. Straatman, Numerical model for non-equilibrium heat and mass exchange in conjugate fluid/solid/porous domains with application to evaporative cooling and drying, Int. J. Heat Mass Transfer 80 (2015) 513-528.

[26] M. Ilic, I.W. Turner, Drying of a wet porous material, Appl. Math. Model. 10 (1) (1986) 16-24.

[27] J.P. Sitompul, Istadi, S. Sumardiono, Modelling and simulation of momentum, heat, and mass transfer in a deep-bed grain dryer, Drying Technol. 21 (2) (2003) 217-229.

[28] J.J. Saastamoinen, Comparison of moving bed dryers of solids operating in parallel and counterflow modes, Drying Technol. 23 (5) (2005) 1003-1025.
[29] W. Zhonghua, A.S. Mujumdar, Simulation of the hydrodynamics and drying in a spouted bed dryer, Drying Technol. 25 (1) (2007) 59-74.

[30] M. Stakić, P. Stefanović, D. Cvetinović, P. Škobalj, Convective drying of particulate solids - packed vs. fluid bed operation, Int. J. Heat Mass Transfer 59 (2013) 66-74.

[31] K. Zhang, C. You, Experimental and numerical investigation of lignite particle drying in a fixed bed, Energy Fuels 25 (9) (2011) 4014-4023.

[32] S. Messai, M. El Ganaoui, J. Sghaier, L. Chrusciel, G. Slimane, Comparison of 1D and 2D models predicting a packed bed drying, Int. J. Simul. Multidiscip. Des. Optim. 5 (2014) A14.

[33] M. Stakić, E. Tsotsas, Modeling and numerical analysis of an atypica convective coal drying process, Drying Technol. 22 (10) (2004) 2351-2373.

[34] Y.A. Cengel, M.A. Boles, Thermodynamics an Engineering Approach, sixth ed., McGraw Hill Company, New York, 2008, pp. 738-747.

[35] D. Velić, M. Planinić, S. Tomas, M. Bilić, Influence of airflow velocity on kinetics of convection apple drying, J. Food Eng. 64 (1) (2004) 97-102.

[36] M. Kaviany, Principles of Heat Transfer in Porous Media, second ed., SpringerVerlag, New York, NY, 1995.

[37] L. Betchen, A.G. Straatman, B.E. Thompson, A nonequilibrium finite-volume model for conjugate fluid/porous/solid domains, Numer. Heat Transfer Part A: Appl. 49 (6) (2006) 543-565.

[38] D.B. Spalding, The combustion of liquid fuels, Symposium (international) on Combustion, vol. 4, Elsevier, 1953, pp. 847-864, No. 1.

[39] F. Incropera, D. Dewitt, T. Bergman, A. Lavine, Fundamentals of Heat and Mass Transfer, 5th ed., Wiley, Hoboken, NJ, 2006, 927.

[40] Z. Pakowski, Z. Bartczak, C. Strumillo, S. Stenström, Evaluation of equations approximating thermodynamic and transport properties of water, steam and air for use in CAD of drying, Drying Technol. 9 (3) (1991) 753-773.

[41] W.G. Whitman, Preliminary experimental confirmation of the two-film theory of gas absorption, Chem. Met. Eng. 29 (1923) 146-148.

[42] Q. Yu, B.E. Thompson, A.G. Straatman, A unit cube-based model for heat transfer and fluid flow in porous carbon foam, J. Heat Transfer 128 (4) (2006) 352-360.

[43] M. Stakić, M. Banjac, T. Urošević, Numerical study on hygroscopic material drying in packed bed, Braz. J. Chem. Eng. 28 (2) (2011) 273-384.

[44] B.A. Fu, M.Q. Chen, Thin-layer drying kinetics of lignite during hot air forced convection, Chem. Eng. Res. Des. 102 (2015) 416-428.

[45] A.S. Ginzburg, I.M. Savina, Moist Transport Characteristics of Food Products Handbook, Light and Food Industry, Moscow, 1982.

[46] T. Defraeye, B. Blocken, J. Carmeliet, Influence of uncertainty in heat-moisture transport properties on convective drying of porous materials by numerical modelling, Chem. Eng. Res. Des. 91 (1) (2013) 36-42.

[47] C.J. Geankoplis, Mass Transport Phenomena, 1978.

[48] M. Toujani, L. Hassini, S. Azzouz, A. Belghith, Experimental and mathematical investigations of apple slices convective drying, J. Food Sci. Eng. 2 (6) (2012) 314.

[49] J.J. Bimbenet, J.D. Daudin, E. Wolff, Air drying kinetics of biological particles, in: Drying'85, Springer, Berlin Heidelberg, 1985, pp. 178-185.

[50] T.R.A. Magee, C.P. Wilkinson, Influence of process variables on the drying of potato slices, Int. J. Food Sci. Technol. 27 (5) (1992) 541-549.

[51] A.G. Yiotis, I.N. Tsimpanogiannis, A.K. Stubos, Y.C. Yortsos, Pore-network study of the characteristic periods in the drying of porous materials, J. Colloid Interface Sci. 297 (2) (2006) 738-748.

[52] S.W. Webb, C.K. Ho, Review of enhanced vapor diffusion in porous media (No SAND-98-1819C; CONF-980559). Sandia National Labs., Albuquerque, NM, United States, 1998.

[53] C. James, C.J. Simonson, P. Talukdar, S. Roels, Numerical and experimental data set for benchmarking hygroscopic buffering models, Int. J. Heat Mass Transfer 53 (19) (2010) 3638-3654.

[54] J. Bochen, Study on the microstructure of thin-layer facade plasters of thermal insulating system during artificial weathering, Constr. Build. Mater. 23 (7) (2009) 2559-2566. 